\title{
A question driven socio-hydrological modeling process
}

\author{
M. Garcia ${ }^{1}$, K. Portney ${ }^{2}$, and S. Islam ${ }^{1,3}$ \\ ${ }^{1}$ Civil \& Environmental Engineering Department, Tufts University, 200 College Avenue, Medford, MA 02155, USA \\ ${ }^{2}$ Bush School of Government \& Public Service, Texas A\&M University, 4220 TAMU, College Station, TX 77843, USA \\ ${ }^{3}$ The Fletcher School of Law and Diplomacy, Tufts University, 160 Packard Avenue, Medford, MA 02155, USA
}

Correspondence to: M. Garcia (margaret.garcia@tufts.edu)

Received: 29 July 2015 - Published in Hydrol. Earth Syst. Sci. Discuss.: 24 August 2015

Revised: 1 December 2015 - Accepted: 7 December 2015 - Published: 15 January 2016

\begin{abstract}
Human and hydrological systems are coupled: human activity impacts the hydrological cycle and hydrological conditions can, but do not always, trigger changes in human systems. Traditional modeling approaches with no feedback between hydrological and human systems typically cannot offer insight into how different patterns of natural variability or human-induced changes may propagate through this coupled system. Modeling of coupled human-hydrological systems, also called socio-hydrological systems, recognizes the potential for humans to transform hydrological systems and for hydrological conditions to influence human behavior. However, this coupling introduces new challenges and existing literature does not offer clear guidance regarding model conceptualization. There are no universally accepted laws of human behavior as there are for the physical systems; furthermore, a shared understanding of important processes within the field is often used to develop hydrological models, but there is no such consensus on the relevant processes in sociohydrological systems. Here we present a question driven process to address these challenges. Such an approach allows modeling structure, scope and detail to remain contingent on and adaptive to the question context. We demonstrate the utility of this process by revisiting a classic question in water resources engineering on reservoir operation rules: what is the impact of reservoir operation policy on the reliability of water supply for a growing city? Our example model couples hydrological and human systems by linking the rate of demand decreases to the past reliability to compare standard operating policy (SOP) with hedging policy (HP). The model shows that reservoir storage acts both as a buffer for variability and as a delay triggering oscillations around a sustainable level of demand. HP reduces the threshold for action thereby decreasing the delay and the oscillation effect. As
\end{abstract}

a result, per capita demand decreases during periods of water stress are more frequent but less drastic and the additive effect of small adjustments decreases the tendency of the system to overshoot available supplies. This distinction between the two policies was not apparent using a traditional noncoupled model.

\section{Introduction}

Humans both respond to and ignore changes in environmental conditions. While humans depend on the natural hydrological cycle to supply water for both personal and economic health (Falkenmark, 1977), they also depend on an array of other natural and human resources to maintain and grow communities. At times water availability can act as the limiting constraint, locally preventing or stalling the expansion of human activity. For example, water availability and variability constrained agricultural development in the Tarim River basin in western China before major water storage and transport infrastructure was constructed (Liu et al., 2014). At other times the water-related risks rise in the background, disconnected from decision making, while other priorities prevail. For instance, the level of the Aral Sea has continued to decline for decades imposing significant costs on adjacent communities but no coordinated effort to stop the decline emerged (Micklin, 2007). At still other times public policy decisions may work to exacerbate water problems, as when decisions are made to keep municipal water prices artificially low or when "senior water rights" encourage water usage in the face of shortages (Chong and Sunding, 2006; Hughes et al., 2013; Mini et al., 2014). 
Human and hydrological systems are coupled. Many impacts of human activity on the hydrological system are now well documented (Tong and Chen, 2002; Wissmar et al., 2004; Vörösmarty et al., 2010; Vahmani and Hogue, 2014) and there is increasing evidence that how and when humans respond individually and collectively to hydrological change has important implications for water resources planning, management and policy (Srinivasan et al., 2010; Di Baldassarre et al., 2013; Elshafei et al., 2014). These observations have prompted a call to treat humans as an endogenous component of the water cycle (Wagener et al., 2010; Sivapalan et al., 2012). Representing water systems as coupled human-hydrological systems or socio-hydrological systems with two-way feedback allows new research questions and potentially transformative insights to emerge.

Traditional modeling approaches assume that there is no feedback between hydrological and human systems and, therefore, cannot provide insights into how different patterns of natural variability or human-induced change may propagate through the coupled system. Over short timescales, such as a year, many human and hydrological variables can be considered constant and their couplings may be ignored (Srinivasan, 2015). However, water resources infrastructure decisions have impacts on longer (decadal to century) timescales; therefore, there is a need for an approach that can handle not only long-term variability and nonstationarity in the driving variables (e.g., precipitation, temperature, population) but also addresses how these changes can propagate through the coupled system, affecting the structure and properties of the coupled system (Sivapalan et al., 2012; Thompson et al., 2013). Dynamic modeling of sociohydrological systems recognizes the potential for humans to transform hydrological systems and for hydrological conditions to influence human behavior. While human behavior is usually incorporated into a model through scenarios, scenarios cannot include two-way feedback. Building effects of human behavior into a simulation model can enable testing of feedback cycles and can illuminate the impact of feedback and path dependencies that are not easily identifiable in scenario-based modeling.

Coupled modeling, on the other hand, introduces new challenges. First, it is not possible to exhaustively model complex systems such as the coupled human-hydrological system (Sterman, 2000; Schlüter et al., 2014). Bounds must be set to develop an effective model but researchers are challenged to objectively define the scope of coupled modeling studies. Second, by definition coupled models cross disciplines and modelers are unable to point to the theoretical framework of any single discipline to defend the relevant scope (Srinivasan, 2015). At the same time researchers must balance the scope and level of detail in order to create a parsimonious and communicable model. Finally, critical assessment of models is more challenging when the theories, empirical methods and vocabulary drawn upon to create and communicate a model span disciplinary boundaries (Schlüter et al., 2014). At the same time, critique is needed to move the field forward as the science is new and lacks established protocols. Transparency of the model aims, the development process, conceptual framework and assumptions are thus particularly important. A structured but flexible modeling process can address these challenges by encouraging modelers to clearly define model objectives, document reasoning behind choices of scale, scope and detail, and take a broad view of potentially influential system processes.

In this paper we present a question driven process for modeling socio-hydrological systems that builds on current modeling tools from both domains and allows the flexibility for exploration. We demonstrate this process by revisiting a classic question in water resources engineering on reservoir operation rules: the tradeoff between standard operating policy (SOP) and hedging policy (HP). Under SOP, demand is fulfilled unless available supply drops below demand; under HP, water releases are reduced in anticipation of a deficit to decrease the risk a large shortfall (Cancelliere et al., 1998). We add to this classic question a linkage between supply reliability and demand. As this question has been asked by numerous researchers before, it offers an excellent opportunity to test the utility of our proposed modeling framework using a hypothetical municipality called Sunshine City as a case study.

\section{Modeling socio-hydrological systems}

Modeling the interactions between human and hydrological systems exacerbates challenges found in modeling purely hydrological systems including setting the model boundary, determining the relevant processes and relationships and clearly communicating model framing and assumptions. Common approaches to hydrological modeling are reviewed to put socio-hydrological modeling in the context of hydrological modeling practice. Next, modeling approaches used in system dynamics and social-ecological systems science, both of which address coupled systems, are described. Then, socio-hydrological modeling approaches are reviewed and gaps identified. While no one approach is directly transferrable to socio-hydrological systems, practices from hydrological modeling, along with those from integrative disciplines, serve as a baseline for comparison and inform our socio-hydrological modeling process. We then present our recommendations for socio-hydrological model conceptualization.

\subsection{Modeling hydrological systems}

In hydrology the basic steps of model development are (a) data collection and analysis, (b) conceptual model development, (c) translation of the conceptual model to a mathematical model, (d) model calibration and (e) model validation (Blöschl and Sivapalan, 1995). While the basic steps 
of model development are generally accepted, in practice approaches diverge, particularly in conceptual model development. In hydrology, Wheater et al. (1993) identified four commonly used modeling approaches: physics-based, concept-based (also called conceptual), data driven and hybrid data-conceptual. Physics-based models represent a system by linking small-scale hydrological processes (Sivapalan et al., 2003). Concept-based models use prior knowledge to specify the influential processes and determine the structure. Data driven models are derived primarily from observations and do not specify the response mechanism. Hybrid dataconceptual models use data and prior knowledge to infer model structure (Wheater et al., 1993; Sivapalan et al., 2003).

Modeling purpose typically determines the modeling approach. Environmental models may be developed to formulate and test theories or to make predictions (Beven, 2002). Physics-based models can be used to test theories about small-scale processes or to predict catchment response by scaling up these processes. Concept-based models hypothesize the important elements and processes and their structure of interaction to answer a question or predict a certain property, although hypotheses are often not explicitly stated and tested (Wheater et al., 1993). A reliance on prior knowledge limits the applicability of concept-based modeling in fields lacking consensus on both the presence and relevance of feedback processes. Data driven models are effective in prediction. While they have potential for hypothesis testing, a focus on black box input-output models limits insight into system processes and the ability to extrapolate beyond observed data (Sivapalan et al., 2003). Hybrid data-conceptual models use data and other knowledge to generate and test hypotheses about the structure of the system (Wheater et al., 1993; Young, 2003). As socio-hydrology is a new area of research, prior knowledge alone is insufficient and the focus is on modeling to enhance understanding through hypothesis generation and testing; hybrid data-conceptual modeling tactics aimed at enhancing understanding therefore inform our proposed process.

\subsection{Modeling coupled systems}

While coupling of natural and human systems is in its infancy in hydrology, there is a strong tradition of studying coupled systems in the fields of system dynamics and socialecological systems. These fields have developed approaches to understand and model complex systems and can inform a socio-hydrological modeling process. First, in both fields the research question or problem drives modeling decisions. Much of the work to date on socio-hydrological systems is exploratory and aims to explain evidence of system coupling seen in case data. Developing a model to answer a question or solve a problem allows a more structured and defensible framework to support the modeling decisions and provides a benchmark for model validation (Sterman, 2000; Hinkel et al., 2015). For example, Jones et al. (2002), in modeling the sawmill industry in the northeastern United States focus on understanding if the system has the structural potential to overshoot sustainable yield. While the resulting model is a significant simplification of a complex system, the reason for inclusion of tree growth dynamics, mill capacity and lumber prices and the exclusion of other variables is clear. Second, system dynamics and social-ecological systems science use multiple data sources, both quantitative and qualitative, to specify and parameterize model relationships. Omitting influential relationships or decision points due to lack of quantitative data results in a greater error than their incorrect specification (Forrester, 1992). Third, system dynamics focuses on developing a dynamic hypothesis that explains the system behavior of interest in terms of feedback processes (Sterman, 2000). Finally, social-ecological systems science has found that the use of frameworks as part of a structured model development process can aid transparency and comparability across models (Schlüter et al., 2014).

\subsection{Progress and gaps in socio-hydrological modeling}

Several research teams have operationalized the concepts of socio-hydrology using approaches ranging from simple generic models to contextual data-driven models. Di Baldassarre et al. (2013) developed a simple generic model to explore the dynamics of human-flood interactions for the purpose of showing that human responses to floods can exacerbate flooding problems. Viglione et al. (2014) extended this work to test the impact of collective memory, risk-taking attitude and trust in risk reduction measures on human-flood dynamics. Kandasamy et al. (2014) analyzed the past 100 years of development in the Murrumbidgee River basin in eastern Australia and built a simple model of the transition from the dominance of agricultural development goals, through a slow realization of adverse environmental impacts, to emergence of serious ecological restoration efforts. Elshafei et al. (2014) proposed a conceptual socio-hydrological model for agricultural catchments and applied it to the Murrumbidgee and the Lake Toolibin basins; they then built upon this conceptual model to construct a detailed semi-distributed model of the Lake Toolibin basin (Elshafei et al., 2015). Srinivasan and collaborators analyzed water security in the city of Chennai, India. By modeling the feedback between household level coping mechanisms and regional-scale stressors, the team explained the counterintuitive effects of policy responses such as the observation that reduced groundwater recharge caused by fixing leaky pipelines decreased a household's ability to use wells to cope with water system interruptions (Srinivasan et al., 2010, 2013).

Researchers have also addressed the methodological questions of how to frame and model socio-hydrological systems. Blair and Buytaert (2015), provide a detailed review of the model types and modeling methods used in sociohydrology and those that may have utility in the field. Sivapalan and Blösch (2015) offer guidance on framing and mod- 
eling socio-hydrological systems from stating framing assumptions to model validation techniques and highlight the specific challenges of scale interactions found in these coupled systems. Elshafei et al. (2014) and Liu et al. (2014) detailed the development of conceptual models, giving readers insight into the framing of their case study work.

These methodological advances have begun to address the many challenges of translating the concept of feedback between human and hydrological systems into actionable science. However, obstacles remain: principally, expanding the scope of modeling to include societal systems and human decision-making exacerbates the challenges of setting the model boundary and process detail, and of evaluating those choices. The source of this challenge is twofold. First, there are fundamental differences between natural and social systems. The laws governing physical, chemical and biological systems such as conservation of mass and energy are broadly applicable across contexts; the relevance of rules influencing social systems varies by context. Second, the modeling of coupled human-hydrological systems is new intellectual territory. At this intersection the norms and unstated assumptions instilled by disciplinary training must be actively questioned and examined within a transparent model development, testing and validation process.

There are no universally accepted laws of human behavior as there are for the physical and biological sciences (Loucks, 2015). While institutions (formal and informal rules) influence behavior, the impact of institutions on the state of the system depends on whether people follow the rules (Schlager and Heikkila, 2011). Additionally, these rules are not static. In response to outcomes of past decisions or changing conditions, actors change both the rules that shape the options available for practical decisions and the rules governing the collective choice process through which these operation rules are made (McGinnis, 2011). Furthermore, water policy decisions are not made in isolation of other policy decisions. Decisions are interlinked as the same actors may interact with and get affected differently depending on the contexts (McGinnis, 2011b). The outcome of a related policy decision may alter the choices available to actors or the resources available to address the current problem. The state of the hydrological system, particularly during extreme events, can spark institutional changes; yet, other factors such as political support and financial resources as well as the preparedness of policy entrepreneurs also play a role (Crow, 2010; Hughes et al., 2013). Given this complexity, Pahl-Wostl et al. (2007) argue that recognizing the unpredictability of policy making and social learning would greatly improve the conceptualization of water management. Nevertheless, some dynamics persist across time and space; water management regimes persist for decades or centuries and some transitions in different locations share characteristics (Elshafei et al., 2014; Kandasamy et al., 2014; Liu et al., 2014). Furthermore, modeling is a useful tool to gain insight into the impacts of these dynamics (Thompson et al., 2013; Sivapalan and
Blöschl, 2015). However, complex systems such as sociohydrological systems cannot be modeled exhaustively (Sterman, 2000; Schlüter et al., 2014). Rather, model conceptualization must balance sufficient process representation and parsimony (Young et al., 1996; Ostrom, 2007).

Model conceptualization is based on general assumptions about how a system works. Often these assumptions are implicit and not challenged by others within the same research community (Kuhn, 1996). This works well when research stays within the bounds of the existing methods, theories and goals of one's research community; when working in new intellectual territory, research community norms cannot be relied upon to guide assumptions. Further disciplinary training is highly successful at teaching these community norms, and researchers working on interdisciplinary projects must actively question the framing assumptions they bring to the project (Lélé and Norgaard, 2005; McConnell et al., 2009). By its integrative nature, socio-hydrological modeling crosses disciplines and modelers are unable to point to the theoretical framework of any single discipline to make simplifying assumptions (Srinivasan, 2015). In absence of research community norms, we must return to modeling fundamentals. Models are simplifications of real systems that, in a strict sense, cannot be validated but the acceptability of model assumptions for the question at hand can be assessed (Sterman, 2000). Careful articulation of the research questions links the assessment of important variables and mechanisms to the question context. This allows the critique to focus on the acceptability of these choices relative to model goals and enables critical assessment of the range of applicability of identified processes through case and model comparison.

The recent Water Resources Research Debate Series offers an excellent illustration of this point. Di Baldassarre et al. (2015) catalyze the debate by presenting a generic model of human-flood interaction. This model incorporates both the "levee effect", in which periods of infrequent flooding (sometimes caused by flood protection infrastructure) increase the tendency for people to settle in the floodplain, and the "adaptation effect", in which the occurrence of flooding leads to an adaptive response. In the model they link flood frequency and adaptive action through a social memory variable which increases with the occurrence of floods and decays slowly overtime; flood occurrence directly triggers levee heightening in technological societies and indirectly, through the social memory, decreases floodplain population density (Di Baldassarre et al., 2015).

In the debate this modeling approach is both commended as an impressive innovation and critiqued for its simplification of social dynamics (Gober and Wheater, 2015; Loucks, 2015; Sivapalan, 2015; Troy et al., 2015). Gober and Wheater (2015) note that while social or collective memory is an important factor in flood resilience it does not determine flood response; flood awareness may or may not result in an adaptive response based on the way individuals, the media 
and institutions process the flood threat, the social capacity for adaptation and the preparedness of policy entrepreneurs, among other factors. Loucks (2015) observes that data on past behavior is not necessarily an indicator of future behavior and suggests that observing stakeholder responses to simulated water management situations may offer additional insight. Troy et al. (2015) and Di Baldassarre et al. (2015) note that the human-flood interaction model presented represents a hypothesis of system dynamics which allows for exploration, and that simple stylized models enable generalization across space and time. In sum, the debate presents different perspectives on the acceptability of the modeling assumptions.

A close look at how the debate authors critique and commend the human-flood interaction model illustrates that the acceptability of modeling assumptions hinges upon the model's intended use. For example, Gober and Wheater (2015) critique the simplicity of social memory as a proxy for social system dynamics but acknowledge the utility of the model in clarifying the tradeoffs of different approaches to meet water management goals. As we can never have comprehensive representation of a complex and coupled human-hydrological system, we need transparency of the abstracting assumptions and their motivation. This is not a new insight; however, a question driven modeling process allows the flexibility and transparency needed to examine the acceptability of model assumptions while acknowledging the role of context and the potential for surprise.

\subsection{A question driven modeling process}

Our proposed process begins with a research question. The research question is then used to identify the key outcome metric(s). A dynamic hypothesis is developed to explain the behavior of the outcome metric over time; a framework can be used to guide and communicate the development of the dynamic hypothesis. Remaining model processes are then specified according to established theory.

As emphasized by both system dynamics and socialecological systems researchers, the research question drives the process of system abstraction. One way to think about this process of abstraction is through the lens of forward and backward reasoning. Schlüter et al. (2014) introduced the idea of forward and backward reasoning to develop conceptual models of social-ecological systems. In a backwardreasoning approach, the question is first used to identify indicators or outcome metrics; next, the analysis proceeds to identify the relevant processes and then the variables and their relationships, as seen in Fig. 1 (Schülter et al., 2014). These three pieces then form the basis for the conceptual model. In contrast, a forward-reasoning approach begins with the identification of variables and relationships and then proceeds toward outcomes. Forward reasoning is most successful when there is expert knowledge of the system, and backward-reasoning is useful primarily when prior knowl-

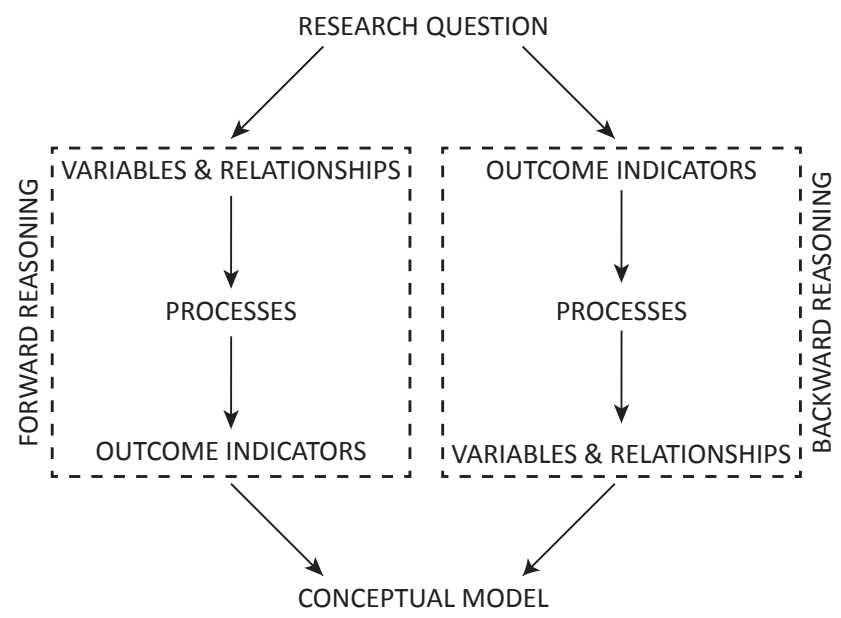

Figure 1. Backward-reasoning process (adapted from Schlüter et al., 2014).

edge is insufficient (Arocha et al., 1993). As few researchers have expert knowledge of all domains involved in sociohydrological modeling and data is often sparse, a backwardreasoning approach is here used to conceptualize a sociohydrological model. Additionally, this outcome-oriented approach will focus the scope of the model on the question's relevant variables and processes.

The research question helps to define the outcome metric(s) of interest; however, determining the relevant processes and variables requires further analysis. One tool to identify influential processes and variables is the dynamic hypothesis. A dynamic hypothesis is a working theory, informed by data, of how the system behavior in question arose (Sterman, 2000). It is dynamic in nature because it explains changes in behavior over time in terms of the structure of the system (Stave, 2003). The dynamic hypothesis could encompass the entire socio-hydrological model, but in practice many processes within a model will be based on established theory such as rainfall runoff or evaporation processes. The intent is to focus the dynamic hypothesis on a novel theory explaining observed behavior. Stating the dynamic hypothesis clarifies which portion of the model is being tested.

A framework can aid the development of the dynamic hypotheses and the communication of the reasoning behind it. The use of frameworks enhances the transparency of model development by clearly communicating the modeler's broad understanding of a system. Socio-hydrological modelers can develop their own framework (Elshafei et al., 2014) or draw on existing frameworks that address coupled humanhydrological systems such as the social-ecological systems (SES) framework, the management transition framework, or the integrated structure-actor-water framework (Ostrom, 2007; Pahl-Wostl et al., 2010; Hale et al., 2015).

To illustrate how a framework may be used in model conceptualization we will focus on the SES framework. The SES 
framework is a nested conceptual map that partitions the attributes of a social-ecological system into four broad classes: (1) resource system, (2) resource units, (3) actors and (4) the governance system (McGinnis and Ostrom, 2014). Each of the four top tier variables has a series of second tier (and potentially higher tier) variables; for example, storage characteristics and equilibrium properties are second tier attributes of the resource system (Ostrom, 2009). The SES framework prescribes a set of elements and general relationships to consider when studying coupled social and ecological systems (Ostrom, 2011). The variables defined in the SES framework were found to impact the interactions and outcomes of social-ecological systems in a wide range of empirical studies (Ostrom, 2007). In addition to specifying candidate variables, the SES framework specifies broad process relationships (Schlüter et al., 2014). At the broadest level, SES specifies that the state of the resource system, governance system, resource unit properties and actor characteristics influence interactions and are subsequently influenced by the outcomes of those interactions. To operationalize the SES framework for model conceptualization one must move down a level to assess the relevance of the tier two variables against case data and background knowledge. This review aims to check the dynamic hypothesis against a broader view of coupled system dynamics and to inform determination of remaining model processes.

The following case presents the development of a sociohydrological (coupled) and a traditional (noncoupled) model to illustrate this process. While this process is developed to study real-world cases a hypothetical case is used here for simplicity, brevity and proof of concept.

\section{Sunshine City: a case study of reservoir operations}

Sunshine City is located in a growing region in a semi-arid climate. The region is politically stable, technologically developed, with a market economy governed by a representative democracy. Sunshine City draws its water supply from the Blue River, a large river which it shares with downstream neighbors. The water users must maintain a minimum flow in the Blue River for ecological health. Sunshine City can draw up to $25 \%$ of the annual flow of the Blue River in any given year. A simple prediction of the year's flow is made by assuming that the flow will be equal to the previous year's flow; the resulting errors are corrected by adjusting the next year's withdrawal.

The city's Water Utility is responsible for diverting, treating and transporting water to city residents and businesses. It is also tasked with making infrastructure investment decisions, setting water prices. Water users receive plentiful supply at cost and there have been no shortages in recent years. While located in a semi-arid environment, the large size of Sunshine City's Blue River water availability and allocation created a comfortable buffer. The city's Water Utility is also
Table 1. Summary of Sunshine City properties.

\begin{tabular}{lrr}
\hline \multicolumn{3}{c}{ Sunshine City properties } \\
\hline Variable & Value & Units \\
\hline Blue River mean flow & 2 & $\mathrm{~km}^{3} \mathrm{yr}^{-1}$ \\
Blue River variance & 0.5 & $\mathrm{~km}^{3} \mathrm{yr}^{-1}$ \\
Blue River lag 1 autocorrelation & 0.6 & - \\
Average evaporation rate & 1 & $\mathrm{~m} \mathrm{yr}^{-1}$ \\
Population & 1000000 & $\mathrm{people}^{\circ}$ \\
Average annual growth rate & 3 & $\%$ \\
Per capita water usage & 400 & $\mathrm{~m}^{3} \mathrm{yr}^{-1}$ \\
Water price & 0.25 & $\mathrm{USD} \mathrm{m}^{-3}$ \\
Reservoir capacity & 0.2 & $\mathrm{~km}^{3}$ \\
Reservoir slope & 0.1 & - \\
\hline
\end{tabular}

responsible for setting water efficiency codes and other conservation rules. The current building code includes only basic efficiencies required by the national government. The Blue River, along with other regional sources, is fully allocated making future augmentation of supplies unlikely. See Table 1 above for a summary of key characteristics of Sunshine City.

Along with the rest of the region, Sunshine City's population, and its water demand, has grown rapidly over the past few years. Managers at the Water Utility are concerned they will no longer be able to meet its reliability targets as demands rise and have added a reservoir to increase future reliability. They now must decide how to operate the reservoir and are considering two options: standard operating policy (SOP) and hedging policy (HP). The selected operating policy must satisfy downstream user rights and maintain minimum ecological flows. In addition to meeting the legal requirements, the Water Utility managers are concerned with finding a policy that will enable the city to provide the most reliable water supply throughout the lifetime of the reservoir (50-100 years). From experience they have observed that both water price and reliability affect demand. A key puzzle that emerges for water managers from this experience is: how do operational rules governing use of water storage influence long-term water supply reliability when consumers make water usage decisions based on both price and reliability?

As the question implies, the Water Utility managers have a working hypothesis relating demand change with water shortages. Therefore, along with the research question the following dynamic hypothesis is considered: the occurrence of water shortages increases the tendency of users to adopt water conservation technologies and to make long-term behavioral changes. HP triggers shortages sooner than SOP thus triggering earlier decreases in demand. 


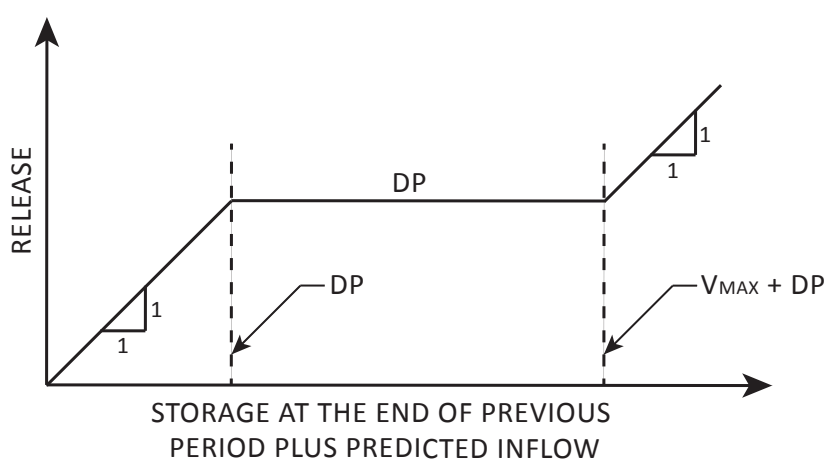

Figure 2. Standard operating policy, where $D$ is per capita demand, $P$ is population and $V_{\max }$ is reservoir capacity (adapted from Shih and ReVelle, 1994).

\subsection{Background}

The decision of how much water to release for use each time period is deceptively complex due to the uncertainty of future streamflows and the nonlinear benefits of released water (Shih and ReVelle, 1994; Draper and Lund, 2004). In making release decisions, water utilities must fulfill their mandate to maintain a reliable water supply in a fiscally efficient manner. Reliability is the probability that the system is in a satisfactory state (Hashimoto et al., 1982). In this case, a satisfactory system state is one in which all demands on the system can be met. The definition of an unsatisfactory state is more nuanced. Water shortages have a number of characteristics that are important to water management including frequency, maximum shortage in a given time period, and length of shortage period (Cancelliere et al., 1998). Longterm reliability here refers to the projected reliability over several decades. The time frame used for long-term projections varies between locations and utilities (i.e., Boston uses a 25 -year time frame, Denver uses a 40-year time frame, and Las Vegas uses a 50-year time frame) and a 50-year time frame is used here (MWRA, 2003; SNWA, 2009; Denver Water, 2015).

Two operational policies, SOP and HP, are commonly used to address this decision problem. Under SOP, demand is always fulfilled unless available supply drops below demand; under HP, water releases are limited in anticipation of an expected deficit (Cancelliere et al., 1998). Hedging is used as a way to decrease the risk of a large shortfall by imposing conservation while stored water remains available. Figures 2 and 3 illustrate SOP and HP, respectively. For this simple experiment only linear hedging, where $K_{\mathrm{P}}$ is the slope of the release function, is tested.

The traditional argument for hedging is that it is economical to allow a small deficit in the current time period in order to decrease the probability of a more severe shortage in a future time periods (Bower et al., 1962). This argument holds true if the loss function associated with a water shortage is

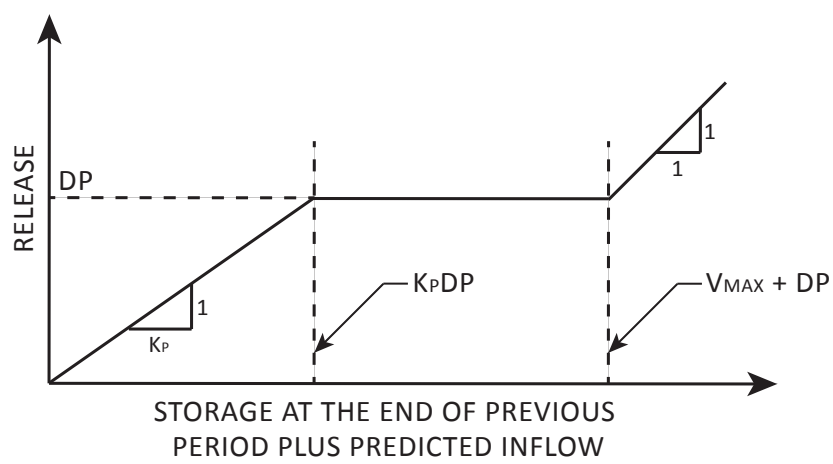

Figure 3. Hedging policy, where $K_{\mathrm{P}}$ is hedging release function slope (adapted from Shih and ReVelle, 1994).

nonlinear and convex; in other words that a severe shortage has a larger impact than the sum of several smaller shortages (Shih and ReVelle, 1994). Gal (1979) showed that the water shortage loss function is convex, thereby proving the utility of hedging as a drought management strategy. Other researchers have shown that hedging effectively reduces the maximum magnitude of water shortages and increases total utility over time (Shih and ReVelle, 1994; Cancelliere et al., 1998). More recent work by Draper and Lund (2004) and You and Cai (2008) confirms previous findings and demonstrates the continued relevance reservoir operation policy selection.

Researchers and water system managers have for decades sought improved policies for reservoir operation during drought periods (Bower et al., 1962; Shih and ReVelle, 1994; You and Cai, 2008). We add to this classic question the observation that water shortages influence both household conservation technology adoption rates and water use behavior. In agreement with Giacomoni et al. (2013), we hypothesize that the occurrence of water shortages increases the tendency of users to adopt water conservation technologies and to make long-term behavioral changes. Household water conservation technologies include low flow faucets, shower heads and toilets, climatically appropriate landscaping, grey water recycling and rainwater harvesting systems (Schuetze and Santiago-Fandiño, 2013). The adoption rates of these technologies are influenced by a number of factors including price, incentive programs, education campaigns and peer adoption (Campbell et al., 2004; Kenney et al., 2008). A review of studies in the US, Australia and UK showed that the installation of conservation technologies results in indoor water savings of $9-12 \%$ for fixture retrofits and $35-50 \%$ for comprehensive appliance replacements (Inman and Jeffrey, 2006). In some cases offsetting behavior reduces these potential gains; however, even with offsetting, the adoption of conservation technologies still results in lower per capita demands (Geller et al., 1983; Fielding et al., 2012). Water use behavior encompasses the choices that individuals make related to water use ranging from length of showers 
Table 2. Household conservation action by shortage experience (ISTPP, 2013).

\begin{tabular}{lrrr}
\hline $\begin{array}{l}\text { Last experienced } \\
\text { a water shortage }\end{array}$ & \multicolumn{3}{c}{$\begin{array}{c}\text { Percent of households, over the } \\
\text { past year, that have }\end{array}$} \\
\cline { 2 - 4 } & $\begin{array}{r}\text { invested in } \\
\text { efficient fixtures } \\
\text { or landscapes }\end{array}$ & $\begin{array}{r}\text { changed } \\
\text { water use } \\
\text { behavior }\end{array}$ & $\begin{array}{r}\text { taken } \\
\text { no } \\
\text { action }\end{array}$ \\
\hline Within a year & $56 \%$ & $88 \%$ & $11 \%$ \\
1-2 years ago & $52 \%$ & $87 \%$ & $11 \%$ \\
2-5 years ago & $51 \%$ & $78 \%$ & $17 \%$ \\
6-9 years ago & $50 \%$ & $79 \%$ & $18 \%$ \\
10 or more years ago & $42 \%$ & $74 \%$ & $24 \%$ \\
Never experienced & $36 \%$ & $66 \%$ & $31 \%$ \\
\hline
\end{tabular}

and frequency of running the dishwasher to timing of lawn watering and frequency of car washing. Water use behavior is shaped by knowledge of the water system, awareness of conservation options and their effectiveness, and consumer's attitudes toward conservation (Frick et al., 2004; Willis et al., 2011). Changes to water use behavior can be prompted by price increases, education campaigns, conservation regulations and weather (Campbell et al., 2004; Kenney et al., 2008; Olsmtead and Stavins, 2009).

As a city begins to experience a water shortage, the water utility may implement water restrictions, price increases, incentive programs or education campaigns to influence consumer behavior. While staff within the water utility or city may have planned these measures before, the occurrence of a water shortage event, particularly if it aligns with other driving forces, offers a window of opportunity to implement sustainable water management practices (Jones and Baumgartner, 2005; Hughes et al., 2013). In addition, water users are more likely to respond to these measures with changes in their water use behavior and/or adoption of conservation technologies during shortages. Baldassare and Katz (1992) examined the relationship between the perception of risk to personal well-being from an environmental threat and adoption of environmental practices with a personal cost (financial or otherwise). They found that the perceived level of environmental threat is a better predictor for individual environmental action, including water conservation, than demographic variables or political factors. Illustrating this effect, Mankad and Tapsuwan (2011) found that adoption of alternative water technologies, such as on-site treatment and reuse, is increased by the perception of risk from water scarcity.

Evidence of individual level behavior change can also be seen in the results of a 2013 national water policy survey conducted by the Institute for Science, Technology and Public Policy at Texas A\&M University. The survey sampled over 3000 adults from across the United States about their attitudes and actions related to a variety of water resources and public policy issues. Included in the survey were questions that asked respondents how recently, if ever, they person- ally experienced a water shortage and which, if any, household efficiency upgrade or behavioral change actions their household had taken in the past year. Efficiency upgrade options offered included low-flow shower heads, low-flush toilets and changes to landscaping; behavioral options given included shorter showers, less frequent dishwasher or washing machine use, less frequent car washing and changes to yard watering (ISTPP, 2013). As seen in Table 2, respondents who had recently experienced a water shortage were more likely to have made efficiency investments and to have changed their water use behavior. This finding is corroborated by a recent survey of Colorado residents. Of the $72 \%$ of respondents reporting increased attention to water issues, the most-cited reason for the increase ( $26 \%$ of respondents) was a recent drought or dry year (BBC Research, 2013). Other reasons cited by an additional $25 \%$ of respondents including news coverage, water quantity issues and population growth may also be related water shortage concerns or experiences.

The increased receptivity of the public to water conservation measures and the increased willingness of water users to go along with these measures during shortage events combine to drive changes in per capita demands. The combined effect of these two drivers was demonstrated in a study of the Arlington, Texas, water supply system (Giacomoni et al., 2013; Kanta and Zechman, 2014). Additional examples of city- and regional-scale drought response leading to long-term demand decreases include the droughts of 19871991 and the mid-2000s in California and of 1982-1983 and 1997-2009 in Australia (Zilberman et al., 1992; Turral, 1998; Sivapalan et al., 2012; Hughes et al., 2013). It is often difficult to separate the relative effects of the multiple price and nonprice approaches applied by water utilities during droughts (Olmstead and Stavins, 2009). The point is, however, that the response generally points to lower per capita water demands.

One example of lasting water use reductions after a shortage is the 1987-1992 drought in Los Angeles, California. An extensive public awareness and education campaign sparked both behavioral changes and the adoption of efficient fixtures such as low-flow shower heads and toilets and increasing block pricing introduced after the drought helped maintain conservation gains (LADWP, 2010). Evidence of the lasting effect can be seen in Fig. 4. Per capita water demands do not return to 1990 levels after the drought ends in 1992. Note that the data below also contains a counter example. The 19761977 drought caused a sharp drop in water consumption in Los Angeles; however, consumption quickly returned to predrought levels when the rainfall returned in 1978. While the 1976-1977 drought was more intense than any year in the 1987-1992 drought, the long duration of the later drought caused deeper draw downs in the city's water reserves ultimately prompting transformative action (LADWP, 2010). This may indicate that the impact of the 1976-1977 drought was below the threshold for significant action or that other priorities dominated public attention and resources at the 


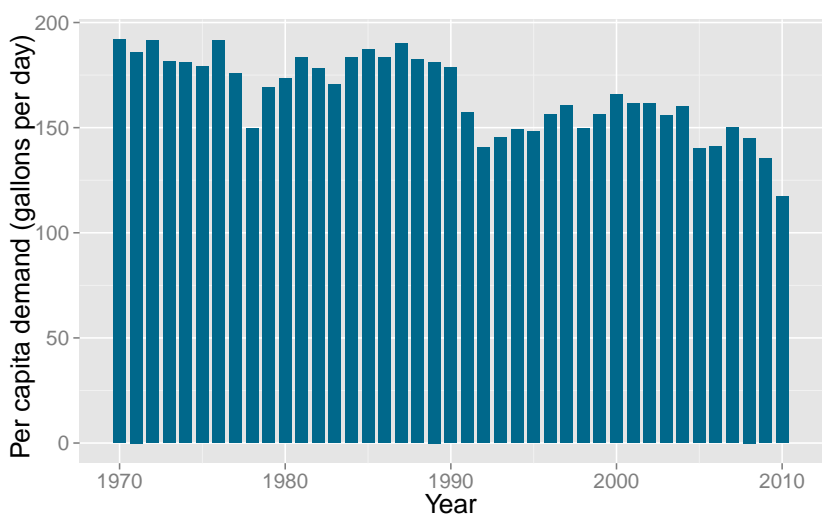

Figure 4. Historical city of Los Angeles water use (LADWP, 2010).

time. In sum, the Los Angeles case serves both to illustrate that hydrological change can prompt long-term changes in water demands and as a reminder that multiple factors influence water demands and hydrological events will not always dominate.

\subsection{Model development}

The Sunshine City water managers want to understand how the operational rules governing use of water storage influence long-term water supply reliability when consumers make water usage decisions based on price and reliability. A model can help the managers gain insight into system's behavior by computing the consequences of reservoir operation policy choice over time and under different conditions. As described in the background section, many supply side and demand side factors affect water system reliability. However, not all variables and processes are relevant for a given question. A question driven modeling process uses the question to determine model boundary and scope rather than beginning with a prior understanding of the important variables and processes. A question driven process is here used to determine the appropriate level of system abstraction for the Sunshine City reservoir operations model.

From the research question it is clear that reliability is the outcome metric of interest and that the model must test for the hypothesized link between demand changes and reliability. Reliability, as defined above, is the percent of time that all demands can be met. The SES framework is used to guide the selection of processes and variables, including the dynamic hypothesis. Given this wide range, the framework was then compared against the variables and processes found to be influential in urban water management and socio-hydrological studies (Brezonik and Stadelmann, 2002; Abrishamchi et al., 2005; Padowski and Jawitz, 2012; Srinivasan et al., 2013; Dawadi and Ahmad, 2013; Elshafei et al., 2014; Gober et al., 2014; Liu et al., 2014; Pande et al., 2013; van Emmerik et al., 2014). Based on this evaluation two second tier variables were added to the framework: land use to the resource system characteristics and water demand to interactions; other variables were modified to reflect the language typically used in the water sciences (i.e., supply in place of harvesting). See Table 3 for urban water specific modification of the SES framework.

We then assess the relevance of the tier two variables against case data and background knowledge (summarized in Sects. 3 and 3.1, respectively) by beginning with the outcome metric, reliability. Within the framework reliability is an outcome variable, specifically a social performance metric, and it is the direct result of water supply and water demand interaction processes. Water supply encompasses the set of utility level decisions on reservoir withdrawals and discharges. As detailed in the case description, these decisions are shaped by the selected reservoir operating policy, streamflow, the existing environmental flow and downstream allocation requirements, reservoir capacity, water in storage and water demands. Streamflow is a stochastic process that is a function of many climatic, hydraulic and land surface parameters. However, given the driving question and the assumption that the city represents only a small portion of the overall watershed, a simple statistical representation is sufficient and streamflow is assumed independent of other model variables.

Total water demand is a function of both population and per capita demand. As described in the background section, per capita water demand changes over time in response to household level decisions to adopt more water efficient technologies and water use behavior change made by individuals in each time interval; these decisions may be influenced by conservation policies. As conditions change water users reassess the situation and, if they choose to act, decide between available options such as investment in efficient technology, changing water use behavior and, in extreme cases, relocation. Therefore, per capita demand is a function of price and historic water reliability as well as available technologies, and water user's perception of the water system. Since the focus of the question is on system wide reliability individual level decisions can be modeled in the aggregate as total demand, which is also influenced by population. Population increases in proportion to the current population, as regional economic growth is the predominant driver of migration trends. However, in extreme cases, perceptions of resource limitations can also influence growth rates. The SES variables used in the conceptual model are highlighted in Table 3 and the resulting processes are summarized in Fig. 5 .

Only a subset of the variables and processes articulated in the SES framework are included in the conceptual model; other variables and processes were considered but not included. For example, economic development drives increasing per capita water demands in many developing regions but the relationship between economic growth and water demands in highly developed regions is weaker due to the increased cost of supply expansion and greater pressure for environmental protection (Gleick, 2000). The income elas- 
Table 3. SES framework, modified for urban water systems.

\begin{tabular}{|c|c|c|}
\hline First tier variables & Second tier variables & Third tier variables (examples) \\
\hline $\begin{array}{l}\text { Socio, economic } \\
\text { and political settings }\end{array}$ & $\begin{array}{l}\text { S1 - Economic development } \\
\text { S2 - Demographic trends } \\
\text { S3 - Political stability } \\
\text { S4 - Other governance systems } \\
\text { S5 - Markets } \\
\text { S6 - Media organizations } \\
\text { S7 - Technology }\end{array}$ & $\begin{array}{l}\text { Per capita income } \\
\text { Rapid growth } \\
\text { Frequency of government turnover } \\
\text { Related regulations } \\
\text { Regional water markets } \\
\text { Media diversity } \\
\text { Infrastructure, communications }\end{array}$ \\
\hline Resource systems ${ }^{1}$ & $\begin{array}{l}\text { RS1 - Type of water resource } \\
\text { RS2 - Clarity of system boundaries } \\
\text { RS3 - Size of resource system } \\
\text { RS4 - Human-constructed facilities } \\
\text { RS5 - Catchment land use } \\
\text { RS6 - Equilibrium properties } \\
\text { RS7 - Predictability of system dynamics } \\
\text { RS8 - Storage characteristics } \\
\text { RS9 - Location }\end{array}$ & $\begin{array}{l}\text { Surface water, groundwater } \\
\text { Groundwater-surface water interactions } \\
\text { Watershed or aquifer size } \\
\text { Type, capacity, condition } \\
\text { Urbanization, reforestation } \\
\text { Mean streamflow, sustainable yield } \\
\text { Data availability, historic variability } \\
\text { Natural/built, volume }\end{array}$ \\
\hline Governance systems ${ }^{2}$ & $\begin{array}{l}\text { GS1 - Government organizations } \\
\text { GS2 - Nongovernment organizations } \\
\text { GS3 - Network structure } \\
\text { GS4 - Water-rights systems } \\
\text { GS5 - Operational-choice rules } \\
\text { GS6 - Collective-choice rules } \\
\text { GS7 - Constitutional-choice rules } \\
\text { GS8 - Monitoring and sanctioning rules }\end{array}$ & $\begin{array}{l}\text { Public utilities, regulatory agencies } \\
\text { Advocacy groups, private utilities } \\
\text { Hierarchy of organizations } \\
\text { Prior appropriation, beneficial use } \\
\text { Water use restrictions, operator protocol } \\
\text { Deliberation rules, position rules } \\
\text { Boundary rules, scope rules } \\
\text { Enforcement responsibility }\end{array}$ \\
\hline Resource units ${ }^{3}$ & $\begin{array}{l}\text { RU1 - Interbasin connectivity } \\
\text { RU2 - Economic value } \\
\text { RU3 - Quantity } \\
\text { RU4 - Distinctive characteristics } \\
\text { RU5 - Spatial and temporal distribution }\end{array}$ & $\begin{array}{l}\text { Infrastructure, surface-groundwater interactions } \\
\text { Water pricing, presence of markets } \\
\text { Volume in storage, current flow rate } \\
\text { Water quality, potential for public health impacts } \\
\text { Seasonal cycles, interannual cycles }\end{array}$ \\
\hline Actors & $\begin{array}{l}\text { A1 - Number of relevant actors } \\
\text { A2 - Socioeconomic attributes } \\
\text { A3 - History or past experiences } \\
\text { A4 - Location } \\
\text { A5 - Leadership/entrepreneurship } \\
\text { A6 - Norms (trust-reciprocity)/social capital } \\
\text { A7 - Knowledge of SES/mental models } \\
\text { A8 - Importance of resource (dependence) } \\
\text { A9 - Technologies available } \\
\text { A10 - Values }\end{array}$ & $\begin{array}{l}\text { Education level, income, ethnicity } \\
\text { Extreme events, government intervention } \\
\text { Presence of strong leadership } \\
\text { Trust in local government } \\
\text { Memory, mental models } \\
\text { Availability of alternative sources } \\
\text { Communication technologies, efficiency technologies } \\
\text { Preservation of cultural practices }\end{array}$ \\
\hline $\begin{array}{l}\text { Action situations: } \\
\text { interactions } \rightarrow \text { outcomes }{ }^{4}\end{array}$ & $\begin{array}{l}\text { I1 - Water supply } \\
\text { I2 - Information sharing } \\
\text { I3 - Deliberation processes } \\
\text { I4 - Conflicts } \\
\text { I5 - Investment activities } \\
\text { I6 - Lobbying activities } \\
\text { I7 - Self-organizing activities } \\
\text { I8 - Networking activities } \\
\text { I9 - Monitoring activities } \\
\text { I10 - Water demand } \\
\text { O1 - Social performance measures } \\
\text { O2 - Ecological performance measures } \\
\text { O3 - Externalities to other SESs }\end{array}$ & $\begin{array}{l}\text { Withdrawal, transport, treatment, distribution } \\
\text { Public meetings, word of mouth } \\
\text { Ballot initiatives, board votes, public meetings } \\
\text { Resource allocation conflicts, payment conflicts } \\
\text { Infrastructure construction, conservation technology } \\
\text { Contacting representatives } \\
\text { Formation of NGOs } \\
\text { Online forums } \\
\text { Sampling, Inspections, self-policing } \\
\text { Indoor/Outdoor, residential/commercial/industrial } \\
\text { Efficiency, equity, accountability } \\
\text { Sustainability, minimum flows } \\
\text { Ecosystem impacts }\end{array}$ \\
\hline Related ecosystems & $\begin{array}{l}\text { ECO1 - Climate patterns } \\
\text { ECO2 - Pollution patterns } \\
\text { ECO3 - Flows into and out of focal SES }\end{array}$ & $\begin{array}{l}\text { El Niño impacts, climate change projections } \\
\text { Urban runoff, upstream discharges } \\
\text { Upstream impacts, downstream rights }\end{array}$ \\
\hline
\end{tabular}

Note: variables added are in italic, variables key to the conceptual model are in bold. Examples of third tier variables are given for clarification. ${ }^{1}$ Resource system variables removed or replaced: productivity of system. ${ }^{2}$ Governance system variables removed or replaced: property. ${ }^{3}$ Resource unit variables removed or replaced: resource unit mobility, growth or replacement rate, interaction among resource units, number of units. ${ }^{4}$ Interaction and outcome variables removed or replaced: harvesting. 

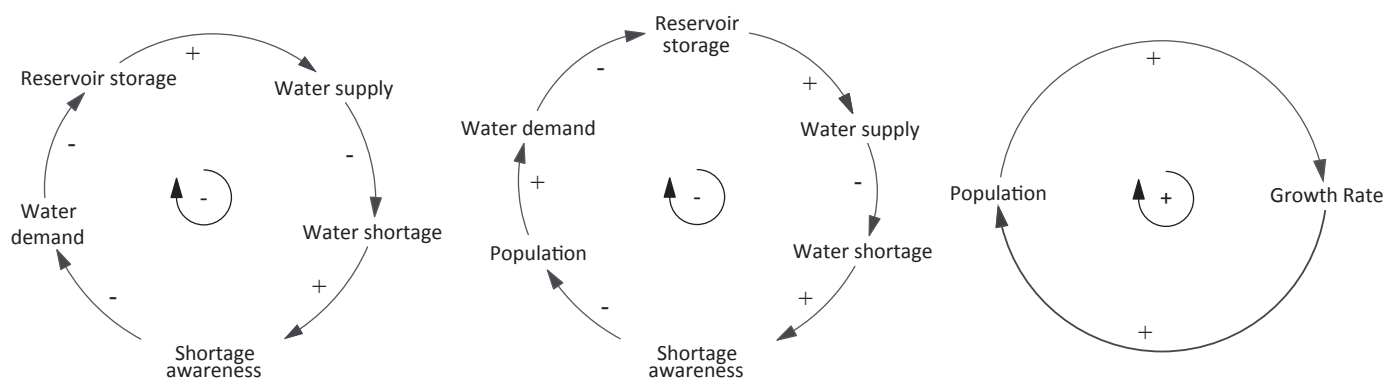

Figure 5. Causal loop diagrams: (a) water demand, shortage and conservation; (b) water demand, shortage and population; (c) population and growth rate.

Table 4. State and exogenous model variables.

\begin{tabular}{lllll}
\hline Variable & Description & Units & Equation & Variable Type \\
\hline$Q$ & Streamflow & $\mathrm{km}^{3} \mathrm{yr}^{-1}$ & 1 & Exogenous \\
$V$ & Reservoir storage volume & $\mathrm{km}^{3}$ & 2 & State \\
$P$ & Population & Persons & 3 & State \\
$W$ & Withdrawal & $\mathrm{km}^{3} \mathrm{yr}^{-1}$ & 4 & State \\
$S$ & Shortage magnitude & $\mathrm{km}^{3} \mathrm{yr}^{-1}$ & 5 & State \\
$M$ & Shortage awareness & & 6 & State \\
$D$ & Per capita demand & $\mathrm{m}^{3} \mathrm{yr}^{-1}$ & 7 & State \\
\hline
\end{tabular}

ticity of water can lead to increased water demands if rates do not change proportionally (Dalhuisen et al., 2003); here prices are assumed to keep pace with inflation. Given this assumption, and the focus on a city in a developed region, economic development likely plays a minor role. Similarly, group decision-making and planning processes such as public forums, voting and elections can shape the responses to reliability changes over time. This model aims to answer a question about the impact of a policy not the ease or likelihood of its implementation. Once the policy is established through whatever process that is used, the question here focuses on its efficacy. Therefore, group decision-making processes need not be included.

In addition to determining the appropriate level of detail of the conceptual model, we must determine which variables change in response to forces outside the model scope (exogenous variables), which variables must be modeled endogenously (state variables) and which can be considered constants (parameters). Again the nature of the question along with the temporal and spatial scale informs these distinctions. Variables such as stored water volume, per capita water demand and shortage awareness will clearly change over the 50 -year study period. The population of the city is also expected to change over the study period. Under average hydrological conditions the population growth rate is expected to be driven predominately by regional economic forces exogenous to the system; however, under extreme conditions water supply reliability can influence the growth rate. Therefore, population is considered a state variable. Streamflow characteristics may change over the 50-year timescale in response to watershed wide land use changes and global-scale climatic changes. Streamflow properties are first considered stationary parameters in order to understand the impact of the selected operating policy in isolation from land use and climate change. Climate scenarios or feedbacks between population and land use can be introduced in future applications of the model to test their impact on system performance. Reservoir operating policy, summarized as the hedging slope, $K_{\mathrm{P}}$, is considered a parameter in the model. Alternate values of parameter $K_{\mathrm{P}}$ are tested but held constant during the study period to understand the long-term impacts of selecting a given policy. Reservoir properties such as capacity and slope are also held constant to hone in on the effect of operating policy. See Tables 4 and 5 for a summary of variable types. From these model relationships, general equations are developed by drawing from established theory, empirical findings and working hypotheses.

Streamflow, $Q$, is modeled using a first-order autoregressive model, parameterized by mean $\left(\mu_{\mathrm{H}} \mathrm{km}^{3} \mathrm{yr}^{-1}\right)$, standard deviation $\left(\sigma_{\mathrm{H}} \mathrm{km}^{3} \mathrm{yr}^{-1}\right)$ and lag one autocorrelation $\left(\rho_{\mathrm{H}}\right)$. The final term, $a_{t}$, is a normally distributed random variable with a mean zero and a standard deviation of 1 .

$Q_{t}=\rho_{\mathrm{H}}\left(Q_{t-1}-\mu_{\mathrm{H}}\right)+\sigma_{\mathrm{H}}\left(1-p_{\mathrm{H}}^{2}\right)^{0.5} a_{t}+\mu_{\mathrm{H}}$

At each time step the amount of water in storage, $V$, in the reservoir is specified by a water balance equation, where $W$ is water withdrawal $\left(\mathrm{km}^{3}\right), \eta_{\mathrm{H}}\left(\mathrm{km} \mathrm{yr}^{-1}\right)$ is evaporation, $A$ is area $\left(\mathrm{km}^{2}\right), Q_{\mathrm{D}}\left(\mathrm{km}^{3}\right)$ is downstream demand and $Q_{\mathrm{E}}\left(\mathrm{km}^{3}\right)$ 
Table 5. Model parameters.

\begin{tabular}{llrrr}
\hline Parameters & Description & Value & Units & Equation \\
\hline$\mu_{\mathrm{H}}$ & Mean streamflow & 2.0 & $\mathrm{~km}^{3} \mathrm{yr}^{-1}$ & 1 \\
$\sigma_{\mathrm{H}}$ & Standard deviation of streamflow & 0.5 & $\mathrm{~km}^{3} \mathrm{yr}^{-1}$ & 1 \\
$\rho_{\mathrm{H}}$ & Streamflow lag one autocorrelation & 0.6 & - & 1 \\
$\eta_{\mathrm{H}}$ & Evaporation rate & 0.001 & $\mathrm{~km} \mathrm{yr}^{-1}$ & 2 \\
$Q_{\mathrm{D}}$ & Downstream allocation & $0.50 Q$ & $\mathrm{~km}^{3}$ & 2 \\
$Q_{\mathrm{E}}$ & Required environmental flow & $0.25 Q$ & $\mathrm{~km}^{3}$ & 2 \\
$\sigma_{T}$ & Average slope of reservoir & 0.1 & - & Stage-storage curve \\
$\delta_{\mathrm{I}}$ & Regional birth rate & 0.04 & $\mathrm{yr}^{-1}$ & 3 \\
$\delta_{\mathrm{E}}$ & Regional death rate & 0.03 & $\mathrm{yr}^{-1}$ & 3 \\
$\delta_{\mathrm{I}}$ & Regional immigration rate & 0.05 & $\mathrm{yr}^{-1}$ & 3 \\
$\delta_{\mathrm{E}}$ & Regional emigration rate & 0.03 & $\mathrm{yr}^{-1}$ & 3 \\
$\tau_{\mathrm{P}}$ & Threshold & 0.4 & - & 3 \\
$V_{\mathrm{max}}$ & Reservoir capacity & 2.0 & $\mathrm{~km}^{3}$ & 4 \\
$K_{\mathrm{P}}$ & Hedging slope & Variable & - & 5 \\
$\mu_{S}$ & Awareness loss rate & 0.05 & $\mathrm{yr}^{-1}$ & 6 \\
$\alpha_{\mathrm{D}}$ & Fractional efficiency adoption rate & 0.15 & - & 7 \\
$\beta_{\mathrm{D}}$ & Background efficiency rate & 0.0001 & - & 7 \\
$D_{\mathrm{MIN}}$ & Minimum water demand & 200 & $\mathrm{~m}^{3} \mathrm{yr}^{-1}$ & 7 \\
\hline & & & \\
\hline
\end{tabular}

is the required environmental flow.

$\frac{\mathrm{d} V}{\mathrm{~d} t}=Q_{t}-W_{t}-\eta_{\mathrm{H}} A_{t}-Q_{\mathrm{D}}-Q_{\mathrm{E}}$

Population is the predominant driver of demand in the model. Population $(P)$ changes according to average birth $\left(\delta_{\mathrm{B}}, \mathrm{yr}^{-1}\right)$, death $\left(\delta_{\mathrm{D}}, \mathrm{yr}^{-1}\right)$, emigration $\left(\delta_{\mathrm{E}}, \mathrm{yr}^{-1}\right)$ and immigration $\left(\delta_{\mathrm{I}}, \mathrm{yr}^{-1}\right)$ rates. However, immigration is dampened and emigration accelerated by high values of perceived shortage risk, as would be expected at extreme levels of resource uncertainty (Sterman, 2000). The logistic growth equation, which simulates the slowing of growth as the resource carrying capacity of the system is approached, serves as the basis for the population function. While the logistic function is commonly used to model resource-constrained population growth, the direct application of this function would be inappropriate for two reasons. First, an urban water system is an open system; resources are imported into the system at a cost and people enter and exit the system in response to reductions in reliability and other motivating factors. Second, individuals making migration decisions may not be aware of incremental changes in water shortage risk; rather, perceptions of water stress drive the damping effect on net migration. Finally, only at high levels does shortage perception influence population dynamics. To capture the effect of the open system, logistic damping is applied only to immigration driven population changes when shortage perception crosses a threshold, $\tau_{\mathrm{P}}$. To account for the perception impact, the shortage awareness variable, $M$, is used in place of the ratio of population to carrying capacity typically used; this modi- fication links the damping effect to perceived shortage risk.

$$
\frac{\mathrm{d} P}{\mathrm{~d} t}=\left\{\begin{array}{l}
P_{t}\left[\delta_{\mathrm{B}}-\delta_{\mathrm{D}}+\delta_{\mathrm{I}}-\delta_{\mathrm{E}}\right] \\
P_{t}\left[\left(\delta_{\mathrm{B}}-\delta_{\mathrm{D}}\right)+\delta_{\mathrm{I}}\left(1-M_{t}\right)-\delta_{\mathrm{E}}\left(M_{t}\right)\right] \quad \text { for } M_{t} \geq \tau_{\mathrm{P}}
\end{array}\right.
$$

Water withdrawals, $W$, are determined by the reservoir operating policy in use. As there is only one source, water withdrawn is equivalent to the quantity supplied. The predicted streamflow for the coming year is $0.25 \times Q_{t-1}$, accounting for both downstream demands and environmental flow requirements. Under SOP, $K_{\mathrm{P}}$ is equal to one which sets withdrawals equal to total demand, DP (per capita demand multiplied by population), unless the stored water is insufficient to meet demands. Under HP, withdrawals are slowly decreased once a pre-determined threshold, $K_{\mathrm{P} D P}$, has been passed. For both policies excess water is spilled when stored water exceeds capacity, $V_{\max }$.

$$
\begin{aligned}
& W_{t}= \\
& \left\{\begin{array}{lll}
V_{t}+0.25 Q_{t-1}-V_{\max } & \text { for } & V_{t}+0.25 Q_{t-1} \geq \\
D_{t} P_{t} & \text { for } & D_{t} P_{t}+V_{\max } P_{t}+V_{\max }> \\
V_{t}+0.25 Q_{t-1} & & V_{t}+0.25 Q_{t-1} \geq K_{\mathrm{P}} D_{t} P_{t} \\
K_{\mathrm{P}} & \text { for } & K_{\mathrm{P}} D_{t} P_{t}>V_{t}+0.25 Q_{t-1}
\end{array}\right.
\end{aligned}
$$

When the water withdrawal is less than the quantity demanded by the users, a shortage, $S$, occurs.

$S_{t}= \begin{cases}D_{t} P_{t}-W_{t} & \text { for } D_{t} P_{t}>W_{t} \\ 0 & \text { otherwise }\end{cases}$

Di Baldassarre et al. (2013) observed that in flood plain dynamics awareness of flood risk peaks after a flood event. This model extends that observation to link water shortage 
events to the awareness of shortage risk. The first term in the equation is the shortage impact which is a convex function of the shortage volume. The economic utility of hedging hinges on the assumption that the least costly options to manage demand will be undertaken first. As both water utilities and water users have a variety of demand management and conservation options available and both tend to use options from most to least cost-effective, a convex shortage loss is also applicable to the water users (Draper and Lund, 2004). It is here assumed that the contribution of an event to shortage awareness is proportional to the shortage cost. At high levels of perceived shortage risk only a large shortage will lead to a significant increase in perceived risk. The adaptation cost is multiplied by one minus the current shortage awareness to account for this effect. The second term in the equation incorporates the decay of shortage, $\mu_{\mathrm{S}}\left(\mathrm{yr}^{-1}\right)$, awareness and its relevance to decision making that occurs over time (Di Baldassarre et al., 2013).

$$
\frac{\mathrm{d} M}{\mathrm{~d} t}=\left(\frac{S_{t}}{D_{t} P_{t}}\right)^{2}\left(1-M_{t}\right)-\mu_{S} M_{t}
$$

Historically, in developed regions per capita water demands have decreased over time as technology improved and as water use practices have changed. As described above, this decrease is not constant but rather is accelerated by shocks to the system. To capture this effect there are two portions to the demand change equation: shock-stimulated logistic decay with a maximum rate of $\alpha\left(\mathrm{yr}^{-1}\right)$ and a background decay rate, $\beta\left(\mathrm{yr}^{-1}\right)$. Per capita water demand decrease accelerates in a time interval if water users are motivated by recent personal experience with water shortage (i.e., $M>0$ ). As a certain amount of water is required for basic health and hygiene, there is ultimately a floor to water efficiencies, specified here as $D_{\min }\left(\mathrm{km}^{3} \mathrm{yr}^{-1}\right)$. Reductions in per capita water usage become more challenging as this floor is approached; a logistic decay function is used to capture this effect. When no recent shortages have occurred (i.e., $M=0$ ), there is still a slow decrease in per capita water demands. This background rate, $\beta$, of demand decrease is driven by both the replacement of obsolete fixtures with modern water efficient fixtures and the addition of new more efficient building stock. This background rate is similarly slowed as the limit is approached; this effect is incorporated by using a percentage-based background rate. Note that price is not explicitly included in this formulation of demand. As stated above, because price and nonprice measures are often implemented in concert it is difficult to separate the impacts of these two approaches and in this case unnecessary.

$$
\frac{\mathrm{d} D}{\mathrm{~d} t}=-D_{t}\left[M_{t} \alpha\left(1-\frac{D_{\min }}{D_{t}}\right)+\beta\right]
$$

As a comparison, a noncoupled model was developed. In this model, population and demand changes are no longer modeled endogenously. The shortage awareness variable is removed as it no longer drives population and demand changes. Instead the model assumes that population growth is constant at $3 \%$ and that per capita demands decrease by $0.5 \%$ annually. While these assumptions may be unrealistic they are not uncommon. Utility water management plans typically present one population and one demand projection. Reservoir storage, water withdrawals and shortages are computed according to the equations described above. A full list of model variables and parameters can be found in Tables 4 and 5 , respectively.

\subsection{Results}

The model was run for SOP $\left(K_{\mathrm{P}}=1\right)$ and three levels of HP where level one $\left(K_{\mathrm{P}}=1.5\right)$ is the least conservative, level two $\left(K_{\mathrm{P}}=2\right)$ is slightly more conservative and level three $\left(K_{\mathrm{P}}=3\right)$ is the most conservative hedging rule tested. Three trials were conducted with a constant parameter set to understand the system variation driven by the stochastic streamflow sequence and to test if the relationship hypothesized was influential across hydrological conditions. For each trial streamflow, reservoir storage, shortage awareness, per capita demand, population and total demand were recorded and plotted. As a comparison, each trial was also run in the noncoupled model in which demand and population changes are exogenous.

In the first trial, shown in Fig. 6a, there were two sustained droughts in the study period: from years 5 to 11 and then from years 33 to 37 . Higher than average flows in the years preceding the first drought allowed the utility to build up stored water as seen in Fig. 6b. The storage acts as a buffer and the impacts are not passed along to the water users until year 18 under SOP. Under HP the impacts, as well as water users' shortage awareness, increase in years 15,13 and 12 based on the level of the hedging rule (slope of $K_{\mathrm{P}}$ ) applied, as shown in Fig. 6c. The impact of this rising shortage awareness on per capita water demands is seen in the acceleration of the decline in demands in Fig. 6d. This demand decrease is driven by city level policy changes such as price increases and voluntary restrictions in combination with increased willingness to conserve.

The impacts of this decrease on individual water users will depend on their socio-economic characteristics as well as the particular policies implemented. While the aggregation hides this heterogeneity, it should be considered in the interpretation of these results. The increased shortage awareness also has a small dampening effect on population growth during and directly after the first drought (Fig. 6e). Changes to both per capita demands and population result in total demand changes (see Fig. 6f). After the first drought the system begins to recover under each of the three hedging policies as evidenced by the slow increase in reservoir storage. However, as streamflows fluctuate around average streamflow and total demands now surpass the average allocation, reservoir storage does not recover when no hedging restrictions are 

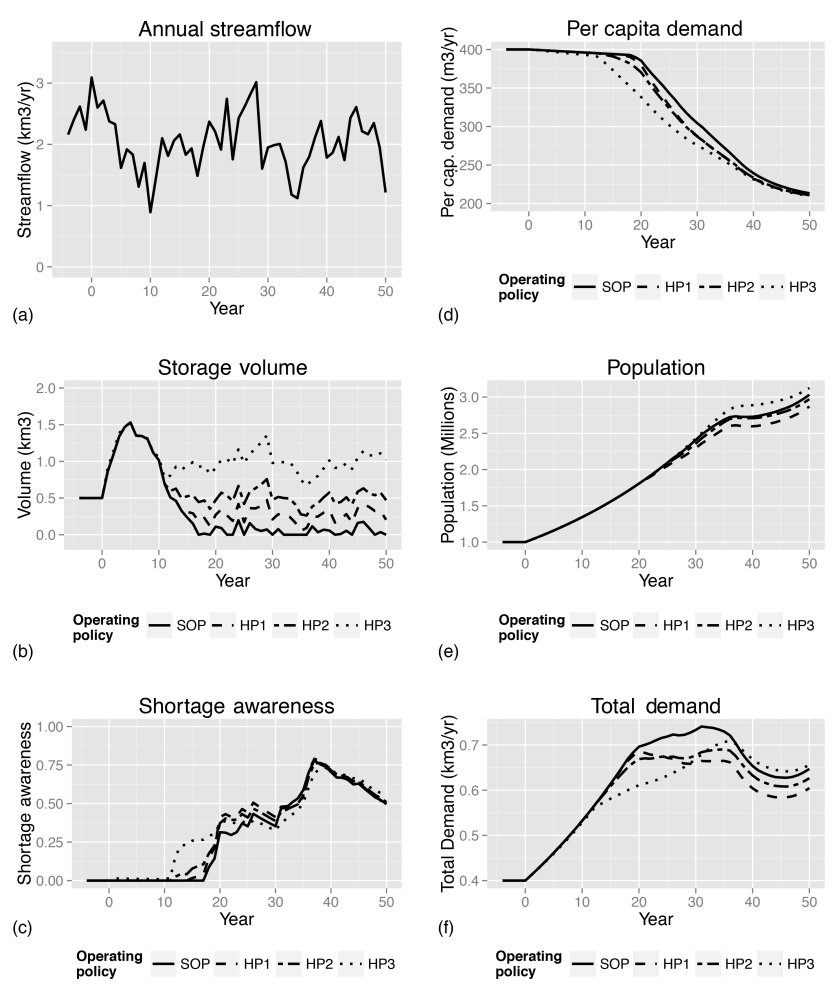

Figure 6. Model results, trial 1: (a) annual streamflow, (b) reservoir storage volume, (c) public shortage awareness, (d) per capita demand, (e) annual city population, (f) total demand.

imposed. Several years of above average flow ending in year 29 drive further recovery. The second prolonged drought has the most pronounced effect under the SOP scenario. Shortage impacts are drastic, driving further per capita demand decreases and a temporary decline in population. A slight population decrease is also seen under level one hedging but the results demonstrate that all hedging strategies dampen the effect.

In the second trial there are two brief droughts in the beginning of the study period, beginning in years 4 and 10, as seen in Fig. 7a. Under SOP and the first two hedging policies there is no change in operation for the first drought and the reservoir is drawn down to compensate as seen in Fig. 7a-b. Only under the level three HP are supplies restricted, triggering an increase in shortage awareness and a subsequent decrease in per capita demands, as found in Fig. 7c and d. When the prolonged drought begins in year 20, the four scenarios have very different starting points. Under SOP, there is less than $0.5 \mathrm{~km}^{3}$ of water in storage and total annual demands are approximately $0.65 \mathrm{~km}^{3}$. In contrast, under the level three HP there is $1.4 \mathrm{~km}^{3}$ of water in storage and total annual demands are just under $0.6 \mathrm{~km}^{3}$. Predictably, the impacts of the drought are both delayed and softened under HP. As the drought is quite severe, all scenarios result in a contraction of population. However, the rate of decrease and total population decrease is lowered by the use of HP.
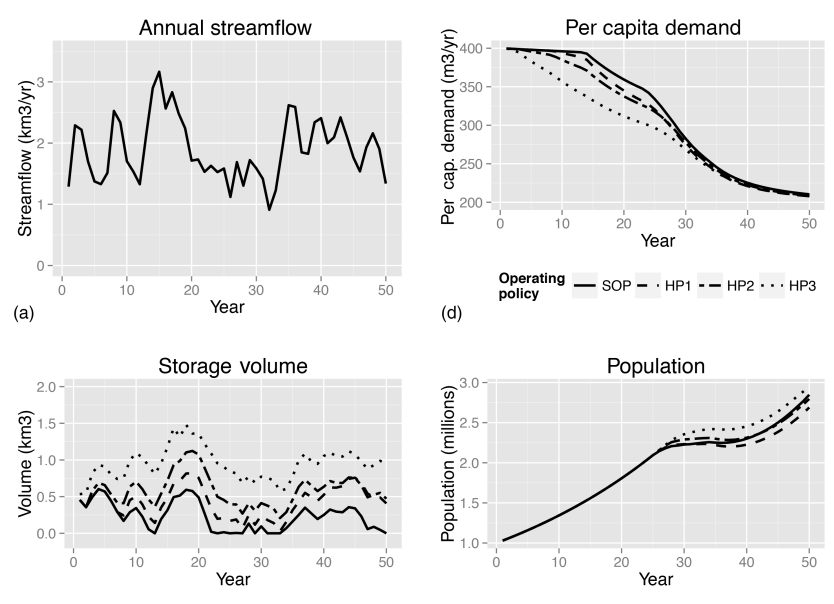

(b)
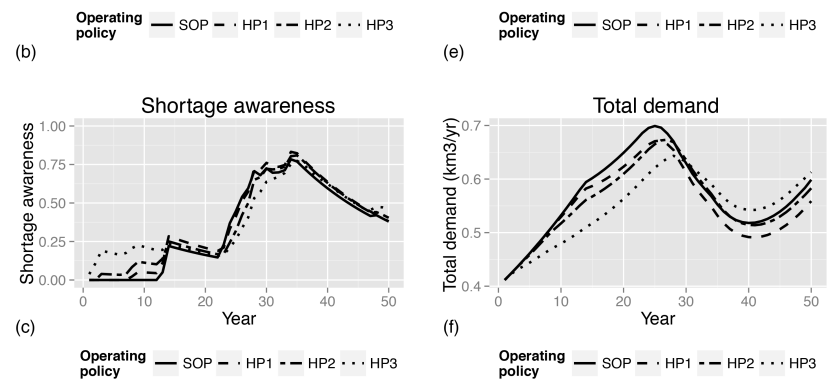

Figure 7. Model results, trial 2: (a) annual streamflow, (b) reservoir storage volume, (c) public shortage awareness, (d) per capita demand, (e) annual city population, (f) total demand.

In the third and final trial there is no significant low flow period until year 36 of the simulation when a moderate drought event occurs, as shown in Fig. 8a. Earlier in the simulation minor fluctuations in streamflow only trigger an acceleration of per capita demand declines under the level three HP, as seen in Fig. 8c and d. A moderate drought begins in year 36. However, the reservoir levels drop and shortage awareness rise starting before year 20, as seen in Fig. $8 \mathrm{~b}$ and c. Then when the drought occurs the impacts are far greater than in the comparably moderate drought in trial 1 because a prolonged period of steady water supply enabled population growth and placed little pressure on the population to reduce demands. In the SOP scenario, the system was in shortage before the drought occurred and total demands peaked in year 30 at $0.82 \mathrm{~km}^{3}$. The subsequent drought exacerbated an existing problem and accelerated changes already in motion.

Figure 9 presents results of the noncoupled model simulation. While the control model was also run for all three trials, the results of only trial three are included here for brevity. In the noncoupled model, HP decreases water withdrawals as reservoir levels drop and small shortages are seen early in the study period, as seen in Fig. 9b and c. In the second half of the study period significant shortages are observed, as in Fig. 9c. However, inspection of the streamflow sequence reveals no severe low flow periods indicating that the shortages are driven by increasing demands, as in Fig. 9a. As ex- 

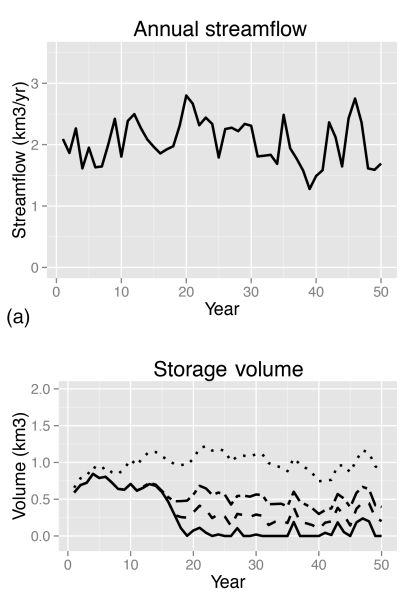

(b)
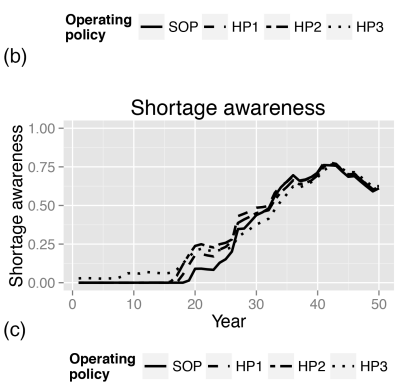
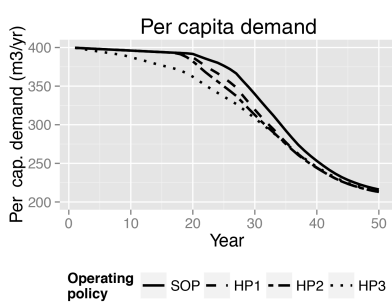

(d)

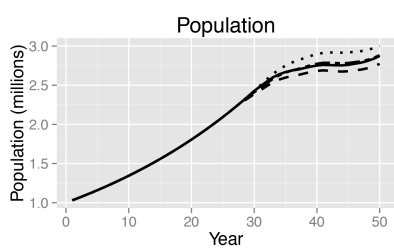

$\underset{\text { policy }}{\text { Operating }}-\mathrm{SOP}-\cdot \mathrm{HP}^{-1}--\mathrm{HP} 2 \cdots \mathrm{HP3}$

(e)

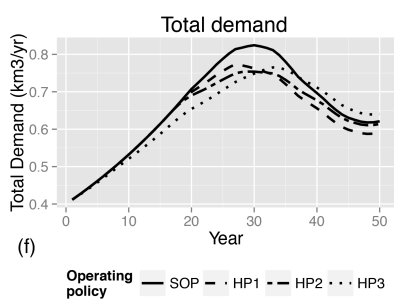

Figure 8. Model results, trial 3: (a) annual streamflow, (b) reservoir storage volume, (c) public shortage awareness, (d) per capita demand, (e) annual city population, (f) total demand.

pected, changes to per capita demands, population, and total demands are gradual and consistent across the operating policy scenarios, found in Fig. 9e and f.

\section{Discussion}

The proposed question driven modeling process has three aims: to broaden the researcher's view of the system, to connect modeling assumptions to the model's purpose and to increase the transparency of these assumptions. A sociohydrological model was developed to examine the difference in long-term reliability between two reservoir operating policies, SOP and HP. This question focused the conceptual model on processes influencing reliability at the city scale over the 50-year planning period. As part of the conceptual model development, the SES framework was used to check framing assumptions. The wide range of candidate variables included in the SES framework was reviewed against case data and background information. The model's intended use then informed decisions of which processes to include in the model, which processes were endogenous to the system and which variables could be held constant. The point here is not that the logic presented by the modeler using this process is unfailing but that it is clear and can inform debate. The questions raised about both the functional form of model re-
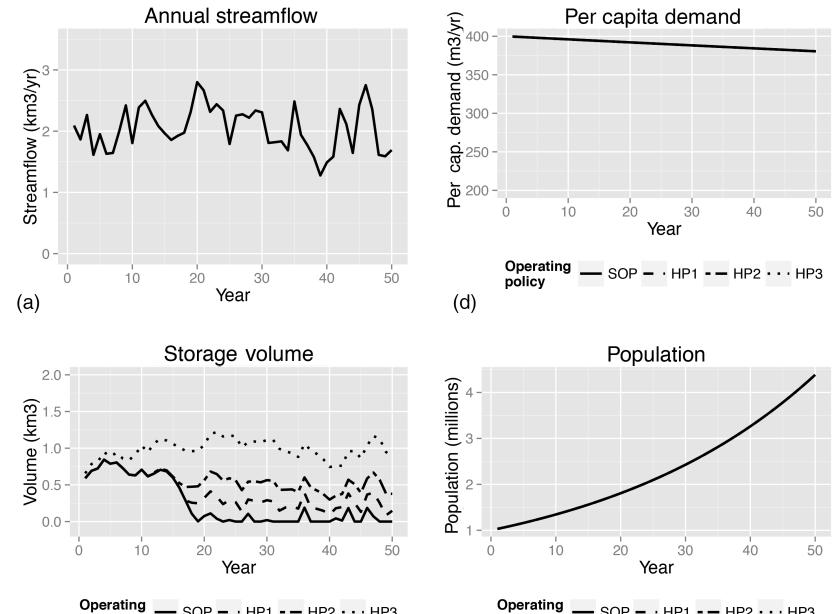

(b)

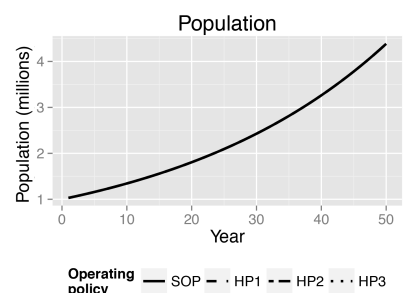

(e)
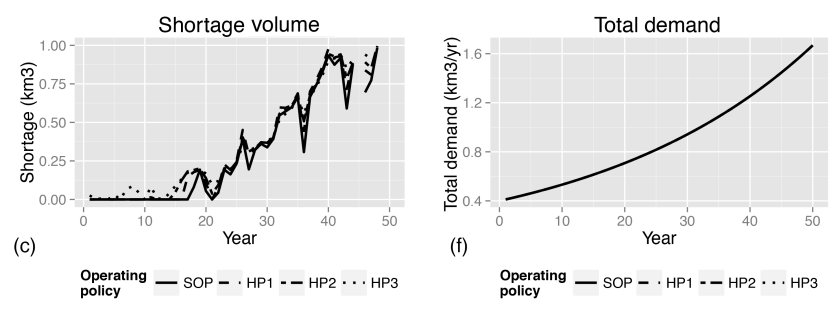

Figure 9. Noncoupled model results, trial 3: (a) annual streamflow, (b) reservoir storage volume, (c) shortage volume (demandsupply), (d) per capita demand, (e) annual city population, (f) total demand.

lationships and the variables excluded during the manuscript review process indicate that some transparency was achieved. However, the reader is in the best position to judge success on this third aim.

A socio-hydrological model of the Sunshine City water system was developed using the question driven modeling process and compared to a noncoupled model. The noncoupled model included assumes that both population growth and per capita demand change can be considered exogenous to the system. Both models show, as prior studies demonstrated, that by making small reductions early on HP reduces the chance of severe shortages. The socio-hydrological model also demonstrates that in the HP scenarios the moderate low flow events trigger an acceleration of per capita demand decrease that shifts the trajectory of water demands and in some instances slows the rate of population growth. In contrast, SOP delays impacts to the water consumers and therefore delays the shift to lower per capita demands. When extreme shortage events, such as a deep or prolonged drought occur, the impacts to the system are far more abrupt in the SOP scenario because per capita demands and population are higher than in hedging scenarios and there is less stored water available to act as a buffer. When we compare SOP and HP using a socio-hydrological model we see that HP decreases the magnitude of the oscillations in demand and population. 
Hedging reduces the threshold for action, thereby decreasing the delay and the oscillation effect. This distinction between the two policies was not apparent when using a traditional noncoupled model. The significance of this observation is that a decrease in oscillation means a decrease in the magnitude of the contractions in population and per capita water demands required to maintain sustainability of the system. It is these abrupt changes in water usage and population that water utilities and cities truly want to avoid as they would hamper economic growth and decrease quality of life.

Examining the structure of the system can explain the differences in system response to SOP and HP. As seen in Fig. 5, there are one positive and two negative feedback loops in the system. Positive feedback loops, such as population in this model, exhibit exponential growth behavior but there are few truly exponential growth systems in nature and through interaction with other feedback loops most systems ultimately reach a limit (Sterman, 2000). Negative feedback loops generate goal seeking behavior. In its simplest form a negative feedback loop produces a slow approach to a limit or goal akin to an exponential decay function. In this case, the goal of the system is to match total demand with average supply. The fact that supply is driven by streamflow, a stochastic variable, adds noise to the system. Even if streamflow is correctly characterized with stationary statistics, as is assumed here, the variability challenges the management of the system. Reservoir storage helps utilities manage this variability by providing a buffer but it also acts as a delay. The delay between a change in the state of the system and action taken in response allows the system to overshoot its goal value before corrective action is taken, leading to oscillation around goal values. While water storage decreases the impact of a drought, changes to water consumption patterns are required to address demand driven shortages. Water storage simultaneously buffers variability and delays water user response by delaying impact. There are parallels between the feedback identified in this urban water supply system and the feedback identified by Elshafei et al. (2014) and Di Baldassarre (2013) in agricultural water management and human-flood interactions, respectively. Broadly, the three systems display the balance between the interaction between opposing forces, in this case articulated as positive and negative feedback loops.

The case of Sunshine City is simplified and perhaps simplistic. The limited number of available options for action constrains the system and shapes the observed behavior. In many cases water utilities have a portfolio of supply, storage and demand management policies to minimize shortages. Additionally, operating policies often shift in response to changing conditions. However, in this case no supply side projects are considered and the reservoir operating policy is assumed constant throughout the duration of the study period. As there are physical and legal limits to available supplies the first constraint reflects the reality of some systems. Constant operational policy is a less realistic constraint but can offer new insights by illustrating the limitations of main- taining a given policy and the conditions in which policy change would be beneficial. Despite these drawbacks a simple hypothetical model is justified here to clearly illustrate the proposed modeling process.

There are several limitations to the hypothetical case of Sunshine City. First, the hypothetical nature of the case precludes hypothesis testing. Therefore, an important extension of this work will be to apply the modeling process presented here on a real case to fully test the resulting model against historical observations before generating projections. Second, only one set of parameters and functions was presented. Future extensions to this work on reservoir policy selection will test the impact of parameter and function selection through sensitivity analysis. Finally, we gain limited understanding of the potential of the model development process by addressing only one research question. We can further test the ability of the modeling process to generate new insights by developing different models in response to different questions. In this case, the narrow scope of the driving question leads to a model that just scratches the surface of socio-hydrological modeling as evidenced by the narrow range of societal variables and processes included. For example, this model does not address the ability of the water utility or city to adopt or implement HP. HP impacts water users in the short term. These impacts would likely generate a mix of reactions from water users and stakeholders making it impossible to ignore politics when considering the feasibility of HP. However, the question driving this model asks about the impact of a policy choice on the long-term reliability of the system not the feasibility of its implementation. A hypothesis addressing the feasibility of implementation would lead to a very different model structure.

While there is significant room for improvement, there are inherent limitations to any approach that models human behavior. The human capacity to exercise free will, to think creatively and to innovate means that human actions, particularly under conditions not previously experienced, are fundamentally unpredictable. Furthermore, as stated above we can never fully capture the complexity of the socio-hydrological system in a model. Instead we propose a modeling process that focuses socio-hydrological model conceptualization on answering questions and solving problems. By using model purpose to drive our modeling decisions we provide justification for simplifying assumptions and a basis for model evaluation.

\section{Conclusions}

Human and water systems are coupled. The feedback between these two subsystems can be, but are not always, strong and fast enough to warrant consideration in water planning and management. Traditional, noncoupled, modeling techniques assume that there is no significant feedback between human and hydrological systems. They therefore 
offer no insights into how changes in one part of the system may affect another. Dynamic socio-hydrological modeling recognizes and aims to understand the potential for feedbacks between human and hydrological systems. By building human dynamics into a systems model, socio-hydrological modeling enables testing of hypothesized feedback cycles and can illuminate the way changes propagate through the coupled system.

Recent work examining a range of socio-hydrological systems demonstrates the potential of this approach. However, there are significant challenges to modeling sociohydrological systems. First, there are no widely accepted laws of human systems as there are for physical or chemical systems. Second, common disciplinary assumptions must be questioned due to the integrative nature of socio-hydrology. Transparency of the model development process and assumptions can facilitate the replication and critique needed to move this young field forward. We assess the progress and gaps in socio-hydrological modeling and draw lessons from adjacent fields of study, hydrology, social-ecological systems science and system dynamics, to inform a question driven model development process. We then illustrate this process by applying it to the hypothetical case of a growing city exploring two alternate reservoir operation rules.

By revisiting the classic question of reservoir operation policy, we demonstrate the utility of a socio-hydrological modeling process in generating new insights into the impacts of management practices over decades. This sociohydrological model shows that HP offers an advantage not detected by traditional simulation models: it decreases the magnitude of the oscillation effect inherent in goal seeking systems with delays. Through this example we identify one class of question, the impact of reservoir management policy selection over several decades, for which socio-hydrological modeling offers advantages over traditional modeling. The model developed, and the resulting insights, are contingent upon the question context. The dynamics identified here may be more broadly applicable but this is for future cases and models to assess.

\section{The Supplement related to this article is available online at doi:10.5194/hess-20-73-2016-supplement.}

Acknowledgements. We would like to thank Brian Fath, Wei Liu, and Arnold Vedlitz for reviewing an early version of this paper. We would also like to thank the two reviewers for their careful reading and thoughtful comments. Financial support for this research comes from the NSF Water Diplomacy IGERT grant (0966093).

Edited by: M. Sivapalan

\section{References}

Abrishamchi, A. and Tajrishi, M.: Inter-basin water transfer in Iran, in: Water Conservation, Reuse, and Recycling, Proceeding of an Iranian American workshop, The National Academies Press, Washington, DC, 252-271, 2005.

Arocha, J. F., Patel, V. L., and Patel, Y. C.: Hypothesis generation and the coordination of theory and evidence in novice diagnostic reasoning, Med. Decis. Making, 13, 198-211, 1993.

Baldassare, M. and Katz, C.: The personal threat of environmental problems as predictor of environmental practices, Environ. Behav., 24, 602-616, 1992.

BBC Research: Public Opinions, Attitudes, and Awareness Regarding Water in Colorado, Final Report Prepared for the Colorado Water Conservation Board, available at: http: //www.bbcresearch.com/images/Final_Report_072213_web.pdf (last access: 1 July 2015), 2013.

Beven, K.: Towards a coherent philosophy for modelling the environment, P. Roy. Soc. A, 458, 2465-2484, doi:10.1098/rspa.2002.0986, 2002.

Blair, P. and Buytaert, W.: Modelling socio-hydrological systems: a review of concepts, approaches and applications, Hydrol. Earth Syst. Sci. Discuss., 12, 8761-8851, doi:10.5194/hessd-12-87612015, 2015.

Blöschl, G. and Sivapalan, M.: Scale issues in hydrological modelling: a review, Hydrol. Process., 9, 251-290, doi:10.1002/hyp.3360090305, 1995.

Bower, B. T., Hufschmidt, M. M., and Reedy, W. W.: Operating procedures: their role in the design of water-resources systems by simulation analyses, in: Design of Water-Resource Systems, Harvard Univ. Press, Cambridge, MA, 443-458, 1962.

Brezonik, P. L. and Stadelmann, T. H.: Analysis and predictive models of stormwater runoff volumes, loads, and pollutant concentrations from watersheds in the Twin Cities metropolitan area, Minnesota, USA, Water Res., 36, 1743-1757, 2002.

Campbell, H. E., Johnson, R. M., and Larson, E. H.: Prices, devices, people, or rules: the relative effectiveness of policy instruments in water conservation, Rev. Policy Res., 21, 637-662, 2004.

Cancelliere, A., Ancarani, A., and Rossi, G.: Susceptibility of water supply reservoirs to drought conditions, J. Hydrol. Eng., 3, 140 $148,1998$.

Chong, H. and Sunding, D.: Water markets and trading, Annu. Rev. Env. Resour., 31, 239-264, doi:10.1146/annurev.energy.31.020105.100323, 2006.

Crow, D. A.: Policy Entrepreneurs, Issue Experts, and Water Rights Policy Change in Colorado, Rev. Policy Research, 27, 299-315, doi:10.1111/j.1541-1338.2010.00443.x, 2010.

Dalhuisen, J. M., Florax, R. J. G. M., de Groot, H. L. F., and Nijkamp, P.: Price and Income Elasticities of Residential Water Demand: A Meta-Analysis, Land Econ., 79, 292-308, doi:10.2307/3146872, 2003.

Dawadi, S. and Ahmad, S.: Evaluating the impact of demand-side management on water resources under changing climatic conditions and increasing population, J. Environ. Manage., 114, 26175, doi:10.1016/j.jenvman.2012.10.015, 2013.

Denver Water: Long-range Planning, available at: http://www. denverwater.org/SupplyPlanning/Planning/, last access: 1 July, 2015.

Di Baldassarre, G., Viglione, A., Carr, G., Kuil, L., Salinas, J. L., and Blöschl, G.: Socio-hydrology: conceptualising human- 
flood interactions, Hydrol. Earth Syst. Sci., 17, 3295-3303, doi:10.5194/hess-17-3295-2013, 2013.

Di Baldassarre, G., Viglione, A., Carr, G., Kuil, L., Yan, K., Brandimarte, L., and Blöschl, G.: Debates-Perspectives on socio-hydrology: Capturing feedbacks between physical and social processes, Water Resour. Res., 51, WR016416, doi:10.1002/2014WR016416, 2015.

Draper, A. J. and Lund, J. R.: Optimal hedging and carryover storage value, J. Water Res. Pl.-ASCE, 130, 83-87, 2004.

Elshafei, Y., Sivapalan, M., Tonts, M., and Hipsey, M. R.: A prototype framework for models of socio-hydrology: identification of key feedback loops and parameterisation approach, Hydrol. Earth Syst. Sci., 18, 2141-2166, doi:10.5194/hess-18-21412014, 2014.

Elshafei, Y., Coletti, J. Z., Sivapalan, M., and Hipsey, M. R.: A model of the socio-hydrologic dynamics in a semiarid catchment: Isolating feedbacks in the coupled humanhydrology system, Water Resour. Res., 6, WR017048, doi:10.1002/2015WR017048, 2015.

Falkenmark, M.: Water and mankind - complex system of mutual interaction, Ambio, 6, 3-9, 1977.

Fielding, K. S., Russell, S., Spinks, A., and Mankad, A.: Determinants of household water conservation: the role of demographic, infrastructure, behavior, and psychosocial variables, Water Resour. Res., 48, W10510, doi:10.1029/2012WR012398, 2012.

Forrester, J. W.: Policies, decisions, and information sources for modeling, Eur. J. Oper. Res., 59, 42-63, 1992.

Frick, J., Kaiser, F. G., and Wilson, M.: Environmental knowledge and conservation behavior: exploring prevalence and structure in a representative sample, Pers. Indiv. Differ., 37, 1597-1613, 2004.

Gal, S.: Optimal management of a multireservoir water supply system, Water. Resour. Res., 15, 737-749, 1979.

Geller, E. S., Erickson, J. B., and Buttram, B. A.: Attempts to promote residential water conservation with educational, behavioral and engineering strategies, Popul. Environ., 6, 96-112, 1983.

Giacomoni, M. H., Kanta, L., and Zechman, E. M.: Complex adaptive systems approach to simulate the sustainability of water resources and urbanization, J. Am. Water Resour. Assoc., 139, 554-564, 2013.

Gleick, P. H.: A Look at Twenty-first Century Water Resources Development, Water Int., 25, 127-138, doi:10.1080/02508060008686804, 2000.

Gober, P. and Wheater, H. S.: Debates-Perspectives on sociohydrology: Modeling flood risk as a public policy problem, Water Resour. Res., 51, WR016945, doi:10.1002/2015WR016945, 2015.

Gober, P., White, D. D., Quay, R., Sampson, D. A., and Kirkwood, C. W.: Socio-hydrology modelling for an uncertain future, with examples from the USA and Canada, Geol. Soc. Spec. Publ., 408, SP408-2, 2014.

Hashimoto, T., Stedinger, J. R., and Loucks, D. P.: Reliability, resiliency, and vulnerability criteria for water resource system evaluation, Water Resour. Res., 18, 14-20, 1982.

Hale, R. L., Armstrong, A., Baker, M. A., Bedingfield, S., Betts, D., Buahin, C., Buchert, M., Crowl, T., Dupont, R. R., Ehleringer, J.R, Endter-Wada, J., Flint, C., Grant, J., Hinners, S., Jeffery, S., Jackson-Smith, D., Jones, A. S., Licon, C., and Null, S. E.: iSAW: integrating structure, actors, and water to study socio-hydro-ecological systems, Earth's Future, 110-132, doi:10.1002/2014EF000295, 2015.

Hinkel, J., Schleuter, M., and Cox, M.: A diagnostic procedure for applying the social-ecological systems framework in diverse cases, Ecol. Soc., 20, 32, doi:10.5751/ES-07023-200132, 2015.

Hughes, S., Pincetl, S., and Boone, C.: Triple exposure: regulatory, climatic, and political drivers of water management changes in the city of Los Angeles, Cities, 32, 51-59, doi:10.1016/j.cities.2013.02.007, 2013.

Inman, D. and Jeffrey, P.: A review of residential water conservation tool performance and influences on implementation effectiveness, Urban Water J., 3, 127-143, 2006.

ISTPP: National Public Water Survey, Institute for Science, Technology and Public Policy, Bush School of Government and Public Service, Texas A \& M University, College Station, TX, 2013.

Jones, B. D. and Baumgartner, F. R.: The Politics of Attention, University of Chicago Press, Chicago, IL, 2005.

Jones, A., Seville, D., and Meadows, D.: Resource sustainability in commodity systems: the sawmill industry in the Northern Forest, Syst. Dynam. Rev., 18, 171-204, doi:10.1002/sdr.238, 2002.

Kandasamy, J., Sounthararajah, D., Sivabalan, P., Chanan, A., Vigneswaran, S., and Sivapalan, M.: Socio-hydrologic drivers of the pendulum swing between agricultural development and environmental health: a case study from Murrumbidgee River basin, Australia, Hydrol. Earth Syst. Sci., 18, 1027-1041, doi:10.5194/hess-18-1027-2014, 2014.

Kanta, L. and Zechman, E.: Complex adaptive systems framework to assess supply-side and demand-side management for urban water resources, J. Water Res. Pl.-ASCE, 140, 75-85, 2014.

Kenney, D. S., Goemans, C., Klein, R., Lowrey, J., and Reidy, K.: Residential water demand management: Lessons from Aurora, Colorado, J. Am. Water Resour. As., 44, 192-207, 2008.

Kuhn, T. S.: The Structure of Scientific Revolutions, 3rd Edn., University of Chicago Press, Chicago, 1996.

LADWP - Los Angeles Department of Water and Power: Urban Water Management Plan 2010, Los Angeles, CA, 2010.

Lélé, S. and Norgaard, R. B.: Practicing Interdisciplinarity, BioScience, 55, 967-975, doi:10.1641/00063568(2005)055[0967:PI]2.0.CO;2, 2005.

Liu, Y., Tian, F., Hu, H., and Sivapalan, M.: Socio-hydrologic perspectives of the co-evolution of humans and water in the Tarim River basin, Western China: the Taiji-Tire model, Hydrol. Earth Syst. Sci., 18, 1289-1303, doi:10.5194/hess-18-12892014, 2014.

Loucks, D. P.: Debates-Perspectives on socio-hydrology: Simulating hydrologic-human interactions, Water Resour. Res., 51, WR017002, 10.1002/2015WR017002, 2015.

Mankad, A. and Tapsuwan, S.: Review of socio-economic drivers of community acceptance and adoption of decentralised water systems, J. Environ. Manage., 92, 380-91, doi:10.1016/j.jenvman.2010.10.037, 2011.

McConnell, W. J., Millington, J. D. A., Reo, N. J., Alberti, M., Asbjornsen, H., Baker, L. A., Brozović, N., Drinkwater, L. E., Scott, A., Fragoso, J., Holland, D. S., Jantz, C. A., Kohler, T. A., Herbert, D., Maschner, G., Monticino, M., Podestá, G., Pontius, R. G., Redman, C. L., Sailor, D., Urquhart, G., and Liu, J.: Research on Coupled Human and Natural Systems (CHANS): Approach, Challenges, and Strategies, B. Ecol. Soc. Am., Meeting Reports, 218-228, 2009. 
McGinnis, M.: Networks of adjacent action situations in polycentric governance, Policy Stud. J., 39, 51-78, doi:10.1111/j.15410072.2010.00396.x/full, 2011.

McGinnis, M.: An Introduction to IAD and the Language of the Ostrom Workshop: A Simple Guide to a Complex Framework, Policy Stud. J., 39, 169-183, doi:10.1111/j.15410072.2010.00401.x, 2011b.

McGinnis, M. D. and Ostrom, E.: Social-ecological system framework: initial changes and continuing challenges, Ecol. Soc., 19, 30, doi:10.5751/ES-06387-190230, 2014.

Micklin, P.: The aral sea disaster, Annu. Rev. Earth Pl. Sc., 35, 4772, doi:10.1146/annurev.earth.35.031306.140120, 2007.

Mini, C., Hogue, T. S., and Pincetl, S.: Patterns and controlling factors of residential water use in Los Angeles, California, Water Policy, 16, 1-16, doi:10.2166/wp.2014.029, 2014.

MWRA - Massachusetts Water Resources Authority: Summary of MWRA Demand Management Program, available at: http:// www.mwra.state.ma.us/harbor/pdf/demandreport03.pdf (last access: 1 July 2015), 2003.

Olmstead, S. M. and Stavins, R. N.: Comparing price and nonprice approaches to urban water conservation, Water Resour. Res., 45, W04301, doi:10.1029/2008WR007227, 2009.

Ostrom, E.: A diagnostic approach for going beyond panaceas, $\mathrm{P}$. Natl. Acad. Sci. USA, 104, 15181-15187, 2007.

Ostrom, E.: A general framework for analyzing sustainability of social-ecological systems, Science, 325, 419-422, doi:10.1126/science.1172133, 2009.

Ostrom, E.: Background on the Institutional Analysis and Development Framework, Policy Stud. J., 39, 7-27, 2011.

Pahl-Wostl, C., Craps, M., Dewulf, A., Mostert, E., Tabara, D., and Taillieu, T.: Social Learning and Water Resources Management, Ecol. Soc., 12, 5, 2007.

Pahl-Wostl, C., Holtz, G., Kastens, B., and Knieper, C.: Analyzing complex water governance regimes: the Management and Transition Framework, Environ. Sci. Policy, 13, 571-581, 2010.

Padowski, J. C. and Jawitz, J. W.: Water availability and vulnerability of 225 large cities in the United States, Water Resour Res, 48, W12529, doi:10.1029/2012WR012335, 2012.

Pande, S. and Ertsen, M.: Endogenous change: on cooperation and water availability in two ancient societies, Hydrol. Earth Syst. Sci., 18, 1745-1760, doi:10.5194/hess-18-1745-2014, 2014.

Schlager, E. and Heikkila, T.: Left High and Dry? Climate Change, Common-Pool Resource Theory, and the Adaptability of Western Water Compacts, Public Admin. Rev., 71, 461-470, doi:10.1111/j.1540-6210.2011.02367.x, 2011.

Schlüter, M., Hinkel, J., Bots, P., and Arlinghaus, R.: Application of the SES framework for model-based analysis of the dynamics of social-ecological systems, Ecol. Soc., 19, 36, doi:10.5751/ES05782-190136, 2014.

Schuetze, T. and Santiago-Fandiño, V.: Quantitative assessment of water use efficiency in urban and domestic buildings, Water, 5, 1172-1193, 2013.

Shih, J. and Revelle, C.: Water-supply operations during drought: continuous hedging rule, J. Water Res. Pl.-ASCE, 120, 613-629, 1994.

Sivapalan, M.: Debates-Perspectives on socio-hydrology: Changing water systems and the "tyranny of small problems"Socio-hydrology, Water Resour. Res., 51, WR017080, doi:10.1002/2015WR017080, 2015.
Sivapalan, M. and Blöschl, G.: Time scale interactions and the coevolution of humans and water, Water Resour. Res., 51, WR017896, doi:10.1002/2015WR017896, 2015.

Sivapalan, M., Blöschl, G., Zhang, L., and Vertessy, R.: Downward approach to hydrological prediction, Hydrol. Process., 17, 21012111, doi:10.1002/hyp.1425, 2003.

Sivapalan, M., Savenije, H. H. G., and Blöschl, G.: Sociohydrology: A new science of people and water, Hydrol. Process., 26, 1270-1276, 2012.

SNWA - Southern Nevada Water Authority: Water Resources Management Plan, available at: http://www.snwa.com/assets/pdf/wr plan.pdf (last access: 1 July 2015), 2009.

Srinivasan, V., Gorelick, S. M., and Goulder, L.: Sustainable urban water supply in south India: desalination, efficiency improvement, or rainwater harvesting?, Water Resour. Res., 46, W10504, doi:10.1029/2009WR008698, 2010.

Srinivasan, V., Seto, K. C., Emerson, R., and Gorelick, S. M.: The impact of urbanization on water vulnerability: A coupled human-environment system approach for Chennai, India, Global Environ. Chang., 23, 229-239, doi:10.1016/j.gloenvcha.2012.10.002, 2013.

Srinivasan, V.: Reimagining the past - use of counterfactual trajectories in socio-hydrological modelling: the case of Chennai, India, Hydrol. Earth Syst. Sci., 19, 785-801, doi:10.5194/hess19-785-2015, 2015.

Stave, K. A.: A system dynamics model to facilitate public understanding of water management options in Las Vegas, Nevada, J. Environ. Manage., 67, 303-313, doi:10.1016/S03014797(02)00205-0, 2003.

Sterman, J.: Business Dynamics: Systems Thinking and Modeling for a Complex World, Irwin McGraw-Hill, Boston, 2000.

Thompson, S. E., Sivapalan, M., Harman, C. J., Srinivasan, V., Hipsey, M. R., Reed, P., Montanari, A., and Blöschl, G.: Developing predictive insight into changing water systems: useinspired hydrologic science for the Anthropocene, Hydrol. Earth Syst. Sci., 17, 5013-5039, doi:10.5194/hess-17-50132013, 2013.

Tong, S. T. and Chen, W.: Modeling the relationship between land use and surface water quality, J. Environ. Manage., 66, 377-393, 2002.

Troy, T. J., Pavao-Zuckerman, M., and Evans, T. P.: DebatesPerspectives on socio-hydrology: Socio-hydrologic modeling: Tradeoffs, hypothesis testing, and validation, Water Resour. Res., 51, WR017046, doi:10.1002/2015WR017046, 2015.

Turral, H.: Hydro-Logic? Reform in Water Resources Management in Developed Countries with Major Agricultural Water Use Lessons for Developing Nations, Overseas Development Institute, London, 1998.

Vahmani, P. and Hogue, T. S.: Incorporating an urban irrigation module into the Noah Land surface model coupled with an urban canopy model, J. Hydrometeorol., 15, 1440-1456, 2014.

van Emmerik, T. H. M., Li, Z., Sivapalan, M., Pande, S., Kandasamy, J., Savenije, H. H. G., Chanan, A., and Vigneswaran, S.: Socio-hydrologic modeling to understand and mediate the competition for water between agriculture development and environmental health: Murrumbidgee River basin, Australia, Hydrol. Earth Syst. Sci., 18, 4239-4259, doi:10.5194/hess-18-42392014, 2014. 
Viglione, A., Di Baldassarre, G., Brandimarte, L., Kuil, L., Carr, G., Salinas, J. L., Scolobig, A., and Blöschl, G.: Insights from socio-hydrology modelling on dealing with flood risk - roles of collective memory, risk-taking attitude and trust, J. Hydrol., 518, 71-82, doi:10.1016/j.jhydrol.2014.01.018, 2014.

Vörösmarty, C. J., McIntyre, P. B., Gessner, M. O., Dudgeon, D., Prusevich, A., Green, P., Glidden, S., Bunn, S. E., Sullivan, C. A., Lierman, C. R., and Davies, P. M.: Global threats to human water security and river biodiversity, Nature, 467, 555-561, doi:10.1038/nature09549, 2010.

Wagener, T., Sivapalan, M., Troch, P. A., McGlynn, B. L., Harman, C. J., Gupta, H. V., and Wilson, J. S.: The future of hydrology: an evolving science for a changing world, Water Resour. Res, 46, W05301, doi:10.1029/2009WR008906, 2010.

Wheater, H. S., Jakeman, A. J., and Beven, K. J.: Progress and directions in rainfall-runoff modeling, in: Modeling Change in Environmental Systems, John Wiley and Sons, New York, 101-132, 1993.

Willis, R. M., Stewart, R. A., Panuwatwanich, K., Williams, P. R., and Hollingsworth, A. L.: Quantifying the influence of environmental and water conservation attitudes on household end use water consumption, J. Environ. Manage., 92, 1996-2009, 2011.
Wissmar, R. C., Timm, R. K., and Logsdon, M. G.: Effects of changing forest and impervious land covers on discharge characteristics of watersheds, Environ. Manage., 34, 91-98, 2004.

You, J. Y. and Cai, X.: Hedging rule for reservoir operations: 1. A theoretical analysis, Water Resour. Res., 44, 1-9, 2008.

Young, P., Parkinson, S., and Lees, M.: Simplicity out of complexity in environmental modelling: Occam's razor revisited, J. Appl. Stat., 23, 165-210, doi:10.1080/02664769624206, 1996.

Young, P.: Top-down and data-based mechanistic modelling of rainfall-flow dynamics at the catchment scale, Hydrol. Process., 17, 2195-2217, doi:10.1002/hyp.1328, 2003.

Zilberman, D., Dinar, A., MacDougall, N., Khanna, M., Brown, C., and Castillo, F.: Individual and institutional responses to the drought: The case of California agriculture. ERS Staff Paper, US Department of Agriculture, Washington, DC, 1992. 